\title{
OLD F-AREA SEEPAGE BASIN TRANSPORT ANALYSES IN SUPPORT OF A SCDHEC MIXING ZONE APPLICATION
}

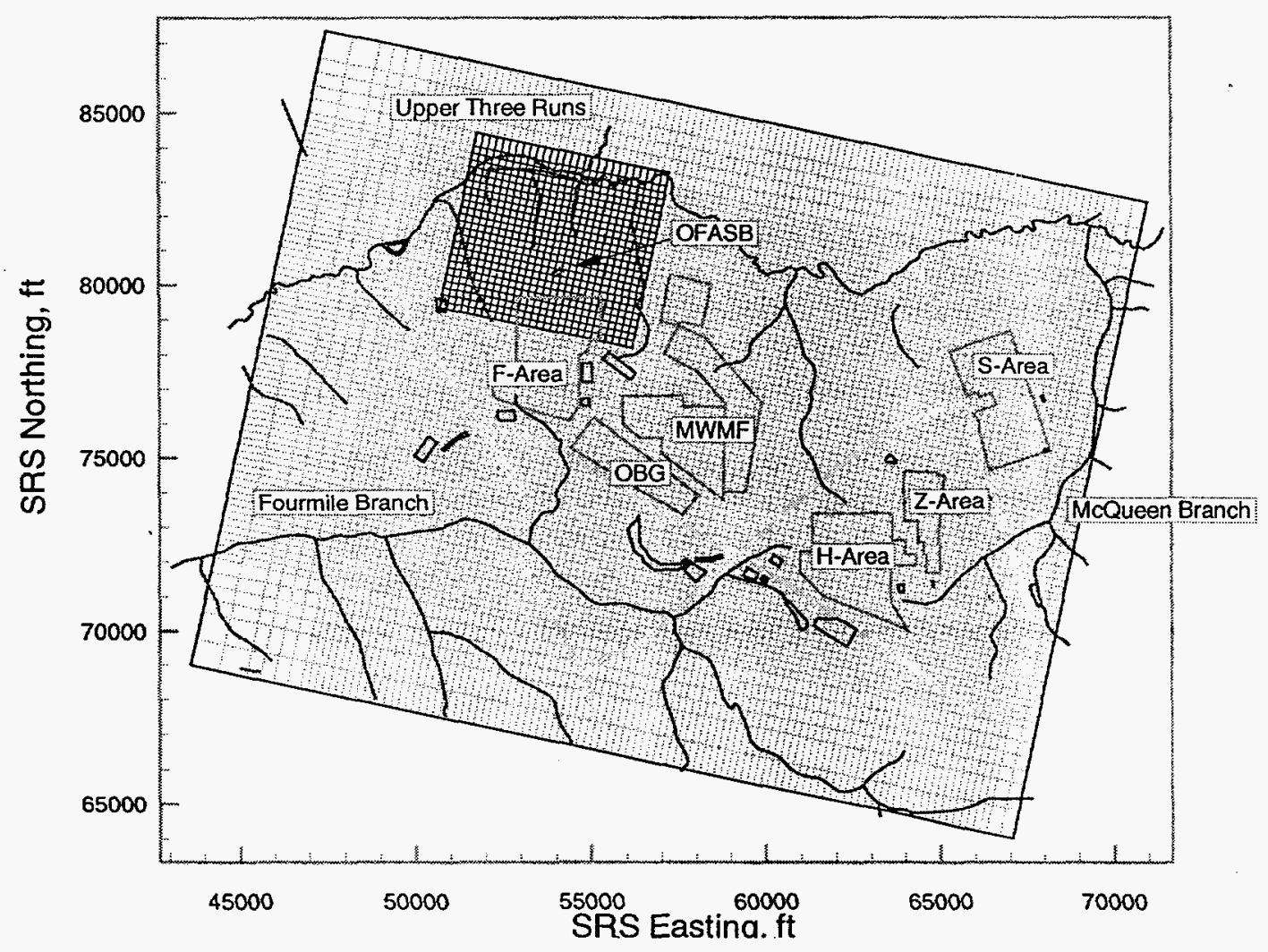

Westinghouse Savannah River Company

Savannah River Site

Aiken, SC 29808

Prepared for the U.S. Department of Energy under Contract No. DE-AC09-89SR18035 


\section{OLD F-AREA SEEPAGE BASIN TRANSPORT ANALYSES IN SUPPORT OF A SCDHEC MIXING ZONE APPLICATION}

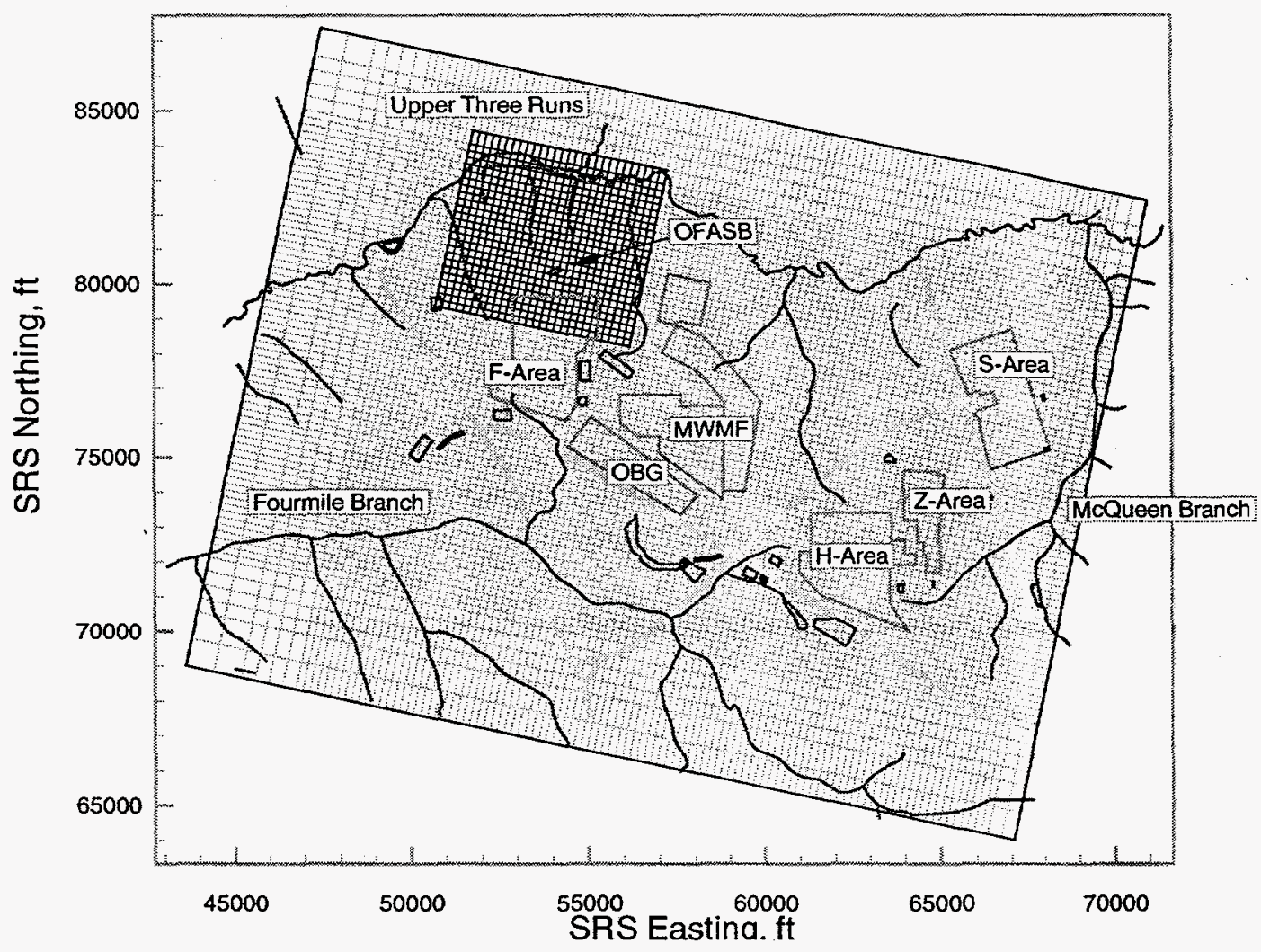

Westinghouse Savannah River Company Savannah River Site Aiken, SC 29808

Prepared for the U.S. Department of Energy under Contract No. DE-AC09-89SR18035 


\section{DISCLAIMER}

This report was prepared as an account of work sponsored by an agency of the United States Government. Neither the United States Government nor any agency thereof, nor any of their employees, makes any warranty, express or implied, or assumes any legal liability or responsibility for the accuracy, completeness, or usefulness of any information, apparatus, product, or process disclosed, or represents that its use would not infringe privately owned rights. Reference herein to any specific commercial product, process, or service by trade name, trademark, manufacturer, or otherwise does not necessarily constitute or imply its endorsement, recommendation, or favoring by the United States Government or any agency thereof. The views and opinions of authors expressed herein do not necessarily state or reflect those of the United States Government or any agency thereof.

This report has been reproduced directly from the best available copy.

Available to DOE and DOE contractors from the Office of Scientific and Technical Information, P.O. Box 62, Oak Ridge, TN 37831; prices available from (615) 576-8401.

Available to the public from the National Technical Information Service, U.S. Department of Commerce, 5285 Port Royal Road, Springfield, VA 22161. 


\section{DISCLAIMER}

Portions of this document may be illegible in electronic image products. Images are produced from the best available original document. 
Keywords:

Groundwater

Old F-Area Seepage Basin

. - FACT Code

Environmental

Mixing Zone

Transport Analysis

Retention: Permanent

\section{OLD F-AREA SEEPAGE BASIN TRANSPORT ANALYSES IN SUPPORT OF A SCDHEC MIXING ZONE APPLICATION}

by

Sebastian E. Aleman

L. Larry Hamm

Gregory P. Flach

Mary K. Harris

Miles E. Denham

Publication Date: September 1998

Westinghouse Savannah River Company

Savannah River Technology Center

Aiken, South Carolina 29808 
WESTINGHOUSE SAVANNAH RIVER COMPANY

Report:

WSRC-TR-98-00307

Revision:

Date:

$09 / 15 / 98$

OFASB MIXING ZONE TRANSPORT ANALYSES

Page:

2 of 56

DOCUMENT: WSRC-TR-98-00307

TITLE: OLD F-AREA SEEPAGE BASIN TRANSPORT ANALYSES IN SUPPORT OF A SCDHEC MIXING ZONE APPLICATION

APPROVALS

$\because$

Date: $9 / 15 / 98$

Sebastian E. Aleman, Author (ERTS/SRTC)

Leary Hamm

Date: $9 / 15 / 98$

L. Larry Hamm, Author (EDS/SRTC)

Date: $9 / 16 / 98$

Gregory P. Flash, Author (ERTS/SRTC)

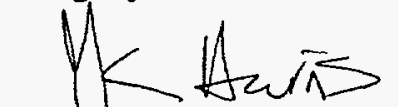

Mary K. Harris, Author (ERTS/SRTC)

Date: $9 / 15 / 98$

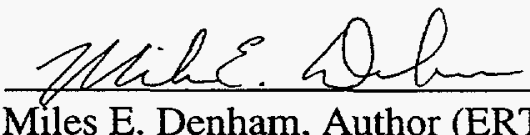

Date: $9 / 15 / 98$

Miles E. Denham, Author (ERTS/SRTC)

Date: $9-16-98$

Joette 9 . Sonnenberg, Manager (ERTS/SRTC)

Date:

Antlia Petbldur with

Date: $9 / 15 / 98$

Cynthia P. Holding-Smith, Manager (EDS/SRTC) 
Executive Summary 7

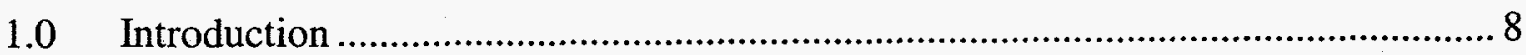

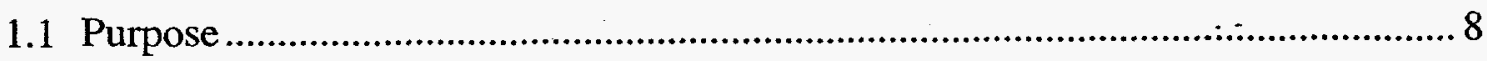

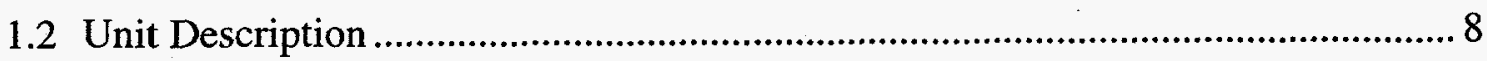

2.0 Groundwater Modeling Overview......................................................................

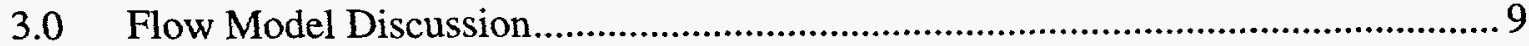

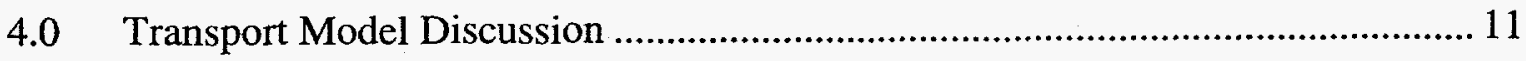

4.1 Transport Model Results .............................................................................. 13

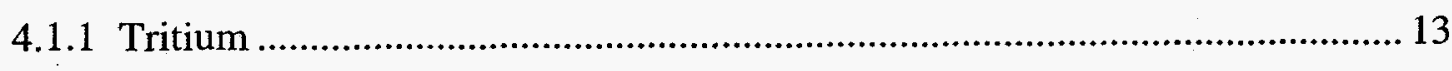

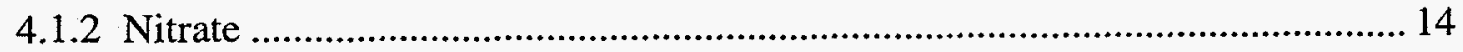

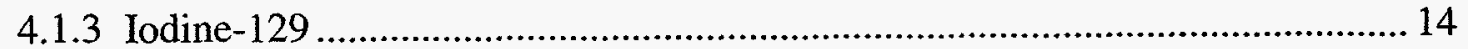

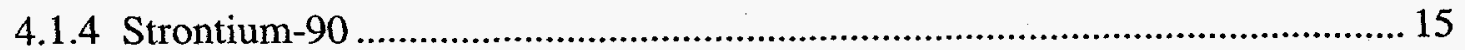

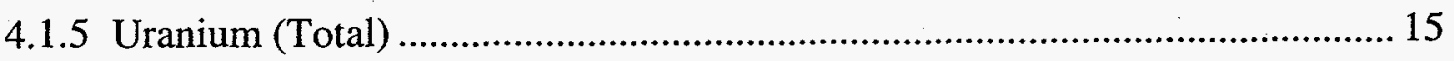

4.2 Quantitative uncertainty analysis ................................................................. 15

4.3 Detailed Discussion of Geochemical Analysis.................................................... 17

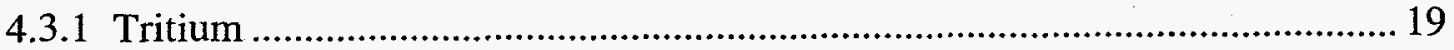

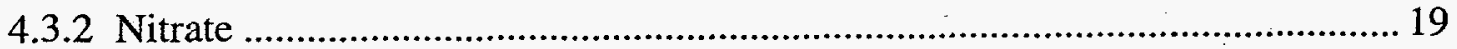

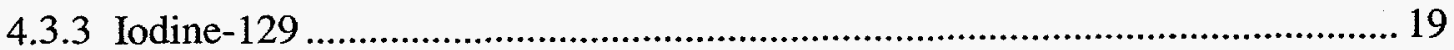

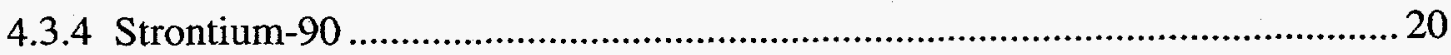

4.3.5 Uranium (Total) ..................................................................................... 20

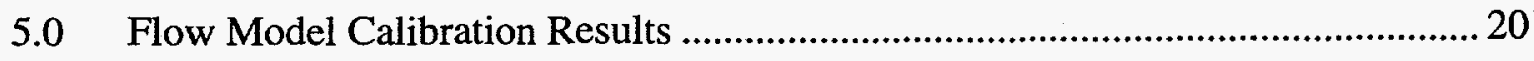

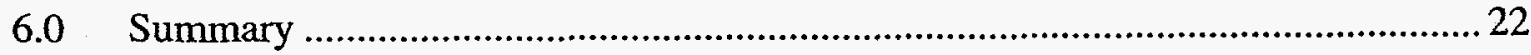

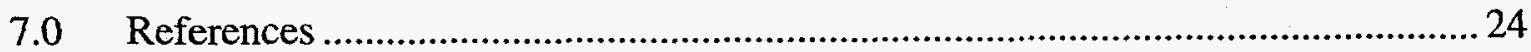


Figure 1: Areal footprints of the GSA flow model and the OFASB flow/transport model based on the FACT code. 27

Figure 2: Topographic features near the Old F-Area Seepage Basin. 28

Figure 3: Location map of the Old F-Area Seepage Basin with monitoring wells, compliance boundary, and OFASB model grid. 28

Figure 4: Simulated vertical groundwater flow paths starting from FNB well screens and hydrostratigraphic nomenclature for OFASB model.

Figure 5: Simulated groundwater flow paths starting from the FNB well screens in the vicinity of OFASB along with simulated and surveyed seep lines.

Figure 6: Simulated 3-D predicted saturated zones and seepage faces............................. 30

Figure 7: Conceptual model for species transport study near OFASB...............................30

Figure 8: Close up showing the location of compliance boundary.

Figure 9: Vertical locations of plume and compliance wells in a North-South crosssection of OFASB model.

Figure 10: Vertical locations of plume and compliance wells in a East-West cross-section of OFASB model.

Figure 11: Initial concentration contours for Tritium.................................................... 33

Figure 12: Initial concentration contours for Nitrate...................................................... 33

Figure 13: Initial concentration contours for Iodine-129. ............................................. 34

Figure 14: Initial concentration contours for Strontium-90. ............................................ 34

Figure 15: Initial concentration contours for total Uranium. ………….......................... 35

Figure 16: Predicted tritium concentration at FNB Point of Compliance wells. .............. 36

Figure 17: Predicted tritium concentration at Compliance Boundary...............................36

Figure 18: Predicted tritium plume conditions in two, four, six, and eight years (plan view).

Figure 19: Predicted tritium plume conditions in two, four, six, and eight years (vertical cross-sectional view).

Figure 20: Predicted nitrate concentration at FNB Point of Compliance wells. 39

Figure 21: Predicted nitrate concentration at Compliance Boundary. 39

Figure 22: Predicted nitrate plume conditions in two, four, six, and eight years (plan view).

Figure 23: Predicted nitrate plume conditions in two, four, six, and eight years (vertical

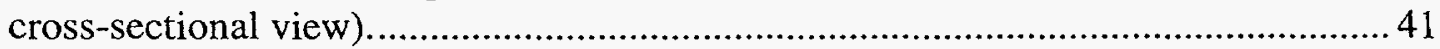

Figure 24: Predicted iodine-129 concentration at FNB Point of Compliance wells. 
Figure 25: Predicted iodine-129 concentration at Compliance Boundary. 42

Figure 26: Predicted iodine-129 plume conditions in 50, 100, 200, and 300 years (plan view).

Figure 27: Predicted iodine-129 plume conditions in 50,100, 200, and 300 years (vertical cross-sectional view).

Figure 28: Predicted strontium-90 concentration at FNB Point of Compliance wells..... 45

Figure 29: Predicted strontium-90 concentration at Compliance Boundary. 45

Figure 30: Predicted strontium-90 plume conditions in 50,100, 150, and 200 years (plan view). 46

Figure 31: Predicted strontium-90 plume conditions in 50,100, 150, and 200 years (vertical cross-sectional view).

Figure 32: Predicted uranium (total) concentration at FNB Point of Compliance wells. 48

Figure 33: Predicted uranium (total) concentration at Compliance Boundary. 48

Figure 34: Predicted uranium (total) plume conditions in 50,150, 250, and 350 years (plan view).

Figure 35: Predicted uranium (total) plume conditions in 50,150, 250, and 350 years (vertical cross-sectional view). 50

Figure 36: Results of sensitivity study for tritium. 51

Figure 37: Results of sensitivity study for nitrate. 51

Figure 38: Results of sensitivity study for iodine-129. 52

Figure 39: Results of sensitivity study for strontium-90. 52

Figure 40: Results of sensitivity study for uranium (total) 53

Figure 41: Plot of Tritium versus nitrate in groundwater of water table wells at F-Area Seepage Basin. 54

Figure 42: Contour plot of measured hydraulic head and seepline data from Upper Three Runs Aquifer $\left(\mathrm{IIB}_{1}\right.$ and $\mathrm{IIB}_{2}$ ) within the GSA. 55

Figure 43: Contour plot of simulated hydraulic head in the "lower" aquifer zone $\left(\mathrm{IBB}_{1}\right) .56$

Figure 44: Contour plot of simulated hydraulic head in the water table. 56 
(This Page Intentionally Left Blank) 


\section{Executive Summary}

A groundwater flow and transport model was developed for the Old $F$ Area Seepage Basin (OFASB) to support the groundwater mixing zone application (GWMZ) submitted to the South Carolina Department of Health and Environmental Control (SCDHEC) in March, 1997. The groundwater flow and subsequent transport simulations provide predictions of the future groundwater contaminant levels to support the GWMZ.

Groundwater modeling was used to predict contaminant concentrations at the compliance boundary, which is down-gradient and within the path of groundwater flow. Predicted concentrations were compared to the maximum concentration limits (MCLs) for each constituent modeled. The plume concentrations at the OFASB have not been increasing. The selected remedial actions for the surface units at the OFASB are stabilization and capping. Therefore the residual contamination left in the soil and groundwater concentrations are expected to decrease to acceptable standards through natural attenuation. A groundwater flow and transport model was required to adequately demonstrate this expected decrease in concentrations.

Groundwater flow and contaminant migration were simulated using a transient threedimensional, finite element computer code. The code, Flow And Contaminant Transport (FACT), (Hamm et al., 1997), has been designed to simulate isothermal groundwater flow, moisture movement, and solute transport in variably saturated and fully saturated subsurface media. The code is designed specifically to handle complex multi-layer and/or heterogeneous aquifer systems in an efficient manner and accommodates a wide range of boundary conditions. Contaminant retardation due to geochemical effects was modeled using a constant distribution coefficient $\left(K_{d}\right)$ and conservative values. The initial plume configuration and concentration levels were defined from concentration contour maps. The vertical extent of contamination was assumed to be 33 feet below the water table (near the bottom of the screen zones in the monitoring wells and approximately half the aquifer thickness). Candidate compliance boundary wells were placed perpendicular to groundwater flow about 1600 feet up-gradient of Upper Three Runs (UTR). The screen zones of these compliance boundary wells are 40 feet in length, nearly fully penetrating. Plume migration was simulated from the present time through break-through at the compliance boundary.

Contamination migration simulations were performed for tritium, nitrate, iodine-129, strontium-90, and uranium. The results from the modeling demonstrated that concentrations of four of the five contaminants would meet existing MCLs at the compliance boundary, with only a slight exceedance of the iodine-129 MCL in one compliance boundary well. The model predicts that concentrations within the existing plume will fall below MCLs within 100 years. 


\subsection{Introduction}

\subsection{Purpose}

This report documents the groundwater flow and transport results presented in the groundwater mixing zone application (GWMZ) for the Old F-Area Seepage Basin (OFASB) submitted to the South Carolina Department of Health and Environmental Control (SCDHEC) in March, 1997 (WSRC,1997). The remedial action objective (RAO) for the groundwater beneath. the OFASB is that, through natural attenuation, the concentrations of the contaminants is the groundwater will decrease to levels at or below the remedial goal options (RGOs) specified for the contaminants of interests.

The selected remedial action for the surface unit consists of stabilizing the contaminated soils within the basin, filling the basin with clean soil, and capping the basin. Although groundwater concentrations beneath the OFASB have exceeded MCLs in previous sampling events, the concentrations of contaminants have not been increasing over time. The remedial actions selected for the surface unit will reduce the potential for further contamination by stabilizing the contaminants and by significantly reducing infiltration through the contaminated soil. In addition, through institutional controls the selected remedy will control potential human exposure to contaminants during the time period when the groundwater mixing zone is in effect. During this time, radiological and chemical degradations, dilution, and sorption to soil particles in the aquifer should be sufficient to provide passive aquifer restoration within a period of 2 to 115 years.

Mixing Zone Concentration Limits (MZCLs) are established for those contaminants that exceeded MCLs during the sampling events reported in the Resource Conservation and Recovery Act (RCRA) Facility Investigation/Remedial Investigation (RFI/RI), (WSRC 1995) and which continue to exceed MCLs in subsequent sampling events. Additionally, this application outlines a long-term monitoring program utilizing the existing monitoring well network, as well as a series of monitoring wells to be installed the compliance boundary and at a location between the OFASB and the compliance boundary.

The groundwater flow and subsequent transport simulations provide predictions of the future groundwater contaminant levels to support the GWMZ. For a complete overview of the regulatory history and GWMZ application the reader is referred to WSRC-RP-97$39, \operatorname{Rev} 1$.

\subsection{Unit Description}

A complete unit description and unit history can be found in the OFASB CMS/FS Report (WSRC, 1996). This sections provides a brief unit description of the model area that are relevant to the GWMZ. The OFASB is located in the General Separations Area (GSA) north of F Area (Figure 1). The OFASB is located at the top of a gentle slope at an elevation of 285 feet above mean sea level (msl) (Figure 2). Surface drainage is to the 
north toward Upper Three Runs (UTR). The topography between the OFASB and the wetland area near UTR slopes sharply (Figure 2).

The water table is approximately 75 feet below ground surface in the area of the OFASB. Groundwater flow for the water table is north toward UTR with a horizontal hydraulic gradient of 0.02 . Estimates of hydraulic conductivity for the water table range from 0.66 to $4.25 \mathrm{ft} /$ day. Total porosity of the sediments range approximately from 0.35 to 0.60 . Effective porosity values range approximately from 0.20 to 0.40 (WSRC 1996a).

\subsection{Groundwater Modeling Overview}

Groundwater modeling was used to predict contaminant concentrations at the compliance boundary, which is down-gradient and within the path of groundwater flow. Because the plume concentrations have not been increasing and the selected remedial action for the surface units includes stabilizing and capping the residual contamination left in the soil, groundwater concentrations are expected to decrease to acceptable standards through natural attenuation. A groundwater flow and transport model was required to adequately demonstrate this expected decrease in concentrations.

Groundwater flow and contaminant migration were simulated using a transient threedimensional, finite element computer code. The code, Flow And Contaminant Transport (FACT), (Hamm et al., 1997), has been designed to simulate isothermal groundwater flow, moisture movement, and solute transport in variably saturated and fully saturated subsurface media. The code is designed specifically to handle complex multi-layer and/or heterogeneous aquifer systems in an efficient manner and accommodates a wide range of boundary conditions. An analytical model was not chosen for application to the conditions at the OFASB, because a one-dimensional flow field assumption is not reasonable for the water table conditions between the OFASB and the UTR. The water table moving from the OFASB to UTR drops sharply in elevation and passes beneath the "tan clay" just past the basin.

Contaminant retardation due to geochemical effects was modeled using a constant distribution coefficient $\left(\mathrm{K}_{\mathrm{d}}\right)$ and conservative values. The initial plume configuration and concentration levels were defined from concentration contour maps. The vertical extent of contamination was assumed to be 33 feet below the water table (near the bottom of the screen zones in the monitoring wells and approximately half the aquifer thickness), Candidate compliance boundary wells were placed perpendicular to groundwater flow about 1600 feet up-gradient for the UTR. The screen zones of these compliance boundary wells is 40 feet in length, nearly fully penetrating. Plume migration was simulated from the present time through break-through at the compliance boundary. Discussion and results are presented below.

\subsection{Flow Model Discussion}

Migration of tritium, nitrate, iodine-129, strontium-90, and total uranium from the OFASB to UTR was simulated using a three-dimensional, finite-element, fine-scale groundwater flow and solute contaminant transport model. The simulations were 
produced using an SRS/SRTC code called FACT. Since completion of the OFASB modeling effort the code has been verified and validated with a technically reviewed code manual (Hamm, et al., 1995). The model boundaries cover the distance extending from about 1600' south (up-gradient) of the OFASB to Upper Three Runs, and several thousand feet east and west (Figure 3). Vertically, the model extends from ground surface to the bottom of the Gordon Aquifer Unit (Aquifer Unit IA) (Figure 4). Predicted contaminant plumes are well within these boundaries.

The OFASB groundwater flow model was created by refining a larger scale flow model covering the entire General Separations Area (GSA). Since the OFASB modeling effort the GSA groundwater flow model has been documented (Smits et al., 1997). The GSA model simulates groundwater flow between Fourmile Branch on the south and Upper Three Runs on the north, and between F-area on the west to McQueen Branch on the east. The vertical extent is from ground surface to the bottom of the Gordon Aquifer (Aquifer Unit IIA). The areal resolution of the larger scale GSA model is 200' square. The vertical resolution varies depending on hydrogeologic unit and terrain/stratigraphic variations. The GSA model representation of the "upper" aquifer zone of Upper Three Runs aquifer (aquifer zone $\mathrm{IIB}_{2}$ ) is comprised of 9 finite-elements in the vertical direction. The vadose zone is included in the model. The "lower" aquifer zone (aquifer zone $\mathrm{IB}_{1}$ ) contains 5 finite-elements while the "tan clay" confining zone (confining zone $\mathrm{IIB}_{1}-\mathrm{IB}_{2}$ ) separating the aquifer zones is modeled with 2 vertical elements. The Gordon confining unit (confining unit IIA-IIB) and Gordon aquifer unit (aquifer unit IIA) each contain 2 elements. Hydraulic conductivity values in the GSA model are based on pumping and slug test data, laboratory permeability measurements, and lithologic data. The conductivity field is non-uniform within hydrogeologic units and reflects variations present in the characterization data. The model was calibrated to achieve adequate agreement between measured and simulated values of hydraulic head, recharge and baseflow to area streams.

The groundwater flow model for the OFASB was created by extracting a subset of the GSA model and refining the areal and vertical mesh (Flach and Harris, 1997). The GSA areal grid resolution is $200 \mathrm{ft}$ square with 108 elements along the east-west axis, and 77 elements along the north-south axis. The refined areal grid resolution for the OFASB model varies from 100' around the basin to 200' in peripheral areas (Figure 3). Figure 4 illustrates the hydrostratigraphic nomenclature utilized herein and the number of vertical finite-elements for each hydrostratigraphic zone or unit. The "upper" aquifer zone of Upper Three Runs aquifer (aquifer zone $\mathrm{IB}_{2}$ ) contains 9 vertical finite-elements and includes the vadose zone. The "lower" aquifer zone (aquifer zone $\mathrm{IB}_{1}$ ) contains 10 vertical elements while the "tan clay" confining zone (confining zone $\mathrm{IB}_{1}-\mathrm{IBB}_{2}$ ) separating the aquifer zones is modeled with 2 elements. The Gordon confining unit (confining unit ПA-ПВ) contains 4 vertical elements and the Gordon aquifer unit (aquifer Unit IIA) has 6 elements. Hydraulic heads from the GSA model are used to define head boundary conditions along the perimeter of the OFASB model. Table 3-1 summarizes inputs to the OFASB flow model. Flow model calibration results are presented in the last section of this report. 
Particle tracking indicates that groundwater flows northeast from the OFASB and then turns in a more northerly direction flowing into the unnamed stream that discharges to Upper Three Runs. Travel times of about 10 to 12 years are predicted from the OFASB to the unnamed stream (Figure 5) assuming an effective porosity of 30\%. Figure 4 illustrates the vertical groundwater flow paths from the top and bottom of the FNB well screens in the vicinity of the OFASB. Figure 6 illustrates the topography and simulated seepage faces within the boundaries of the OFASB model. The simulated seepage faces match well with the surveyed seepline areas in the region (Figure 5). Because the Gordon confining unit (confining unit IIA-IIB) is relatively competent from the basin to its outcrop at Upper Three Runs, contaminant migration is confined mainly to the "lower" aquifer zone (aquifer zone $\mathrm{IB}_{1}$ ), (Figure 4).

Table 3-1: Input parameters for OFASB groundwater flow model.

\begin{tabular}{|l|l|l|l|l|}
\hline Input parameter & $\begin{array}{l}\text { Value of } \\
\text { parameter }\end{array}$ & $\begin{array}{l}\text { Uncertainty in } \\
\text { parameter }\end{array}$ & $\begin{array}{l}\text { Model } \\
\text { sensitivity to } \\
\text { parameter }\end{array}$ & $\begin{array}{l}\text { Model } \\
\text { uncertainty from } \\
\text { parameter }\end{array}$ \\
\hline $\begin{array}{l}\text { Horizontal conductivity } \\
\text { UTR aquifer unit; "upper" } \\
\text { zone } \\
\text { UTR aquifer unit; "lower" } \\
\text { zone } \\
\text { Gordon aquifer unit }\end{array}$ & $8.0 \mathrm{ft} / \mathrm{d}$ avg. \\
$8.7 \mathrm{ft} / \mathrm{d}$ avg. & Low & High & Medium \\
\hline $\begin{array}{l}\text { Vertical conductivity } \\
\text { UTR aquifer unit; "tan clay" } \\
\text { zone } \\
\text { Gordon confining unit }\end{array}$ & $\begin{array}{l}0.005 \mathrm{ft} / \mathrm{d} \text { avg. } \\
\text { avg. } \\
1.0 \times 10^{-5} \mathrm{ft} / \mathrm{d} \\
\text { avg. }\end{array}$ & Low & High & Medium \\
\hline Effective porosity & 0.30 & Medium & Low & Low \\
\hline Average recharge & $14.0 \mathrm{in} / \mathrm{yr}$ & Low & High & Medium \\
\hline
\end{tabular}

\subsection{Transport Model Discussion}

The following constituents of concern were provided for the transport simulation:

Tritium

Nitrate $\left(\mathrm{NO}_{3}\right)$

Iodine-129

Strontium-90

Uranium (total)

Starting with an initial dissolved plume, contaminant transport simulations were performed assuming no additional source terms (i.e., vadose zone or up-gradient source). This assumption is consistent with the selected remedy for the source unit. Figure 7 illustrates the conceptual model for species transport study near the OFASB. Contaminant migration was simulated using FACT and the fine-scale mesh and results from the OFASB flow model. Contaminant retardation due to geochemical effects was modeled using a constant $\mathrm{K}_{\mathrm{d}}$ approach and conservative values. Candidate compliance 
boundary wells were placed perpendicular to groundwater flow about 1600' upgradient of Upper Three Runs (Figures 3, 5 and 8). The screen zones of these compliance wells are 40 'in length (nearly fully penetrating) and are designed to capture the core of the plume. Plume migration was simulated from present through at least maximum concentration break-through at the assumed compliance boundary. Figures 9 and 10 illustrate the vertical locations of plume and compliance wells in North-South and East -West crosssectional views. The initial plume configuration and concentration levels were defined from plan view maps (Figures 11-15) and assume that contamination extends from the water table to 33' below the water table (near the bottom of the screen zones in the monitoring wells and approximately half the aquifer thickness). Table 4-1 summarizes transport model inputs.

It is recognized that the constant $\mathrm{K}_{\mathrm{d}}$ approach is simplistic because of the complex nature of geochemical interactions. However, by choosing $\mathrm{K}_{\mathrm{d}}$ values that relate to site conditions and are somewhat conservative, a model is achieved that projects the minimum reasonable retardation. Tritium, nitrate, iodine-129, and strontium- 90 are the contaminants that can be most realistically modeled in a best-estimate sense using this approach. The transport behavior of these contaminants in Savannah River Site groundwater is dominated by adsorption rather than solubility or ion exchange. Further simplifying their transport is the fact that they do not generally form strong complexes with the major ions in solution. Uranium is more difficult to model in a best-estimate sense because of its natural abundance in Savannah River Site sediments and its complicated chemistry. Uranium is subject to solubility constraints, adsorption, multiple valence states, and complexation that additionally complicate modeling efforts. The uncertainty in uranium $\mathrm{K}_{\mathrm{d}}$ is higher compared to the other contaminants as indicated in Table 4-1. However, $4 \mathrm{ml} / \mathrm{g}$ is considered a conservative estimate. 
Table 4-1: Input parameters for OFASB solute transport model.

\begin{tabular}{|c|c|c|c|c|}
\hline Input parameter & $\begin{array}{l}\text { Value of } \\
\text { parameter }\end{array}$ & $\begin{array}{l}\text { Uncertainty in } \\
\text { parameter }\end{array}$ & $\begin{array}{l}\text { Model sensitivity to } \\
\text { parameter }\end{array}$ & $\begin{array}{l}\text { Model uncertainty } \\
\text { from parameter }\end{array}$ \\
\hline $\begin{array}{l}\text { Distribution coeff. } \\
\left(\mathrm{K}_{\mathrm{d}}\right) \\
\text { Tritium } \\
\text { Uranium } \\
\text { Strontium-90 } \\
\text { Iodine-129 } \\
\text { Nitrate }\end{array}$ & $\begin{array}{l}0.001 \mathrm{ml} / \mathrm{g} \\
4 \mathrm{ml} / \mathrm{g} \\
3 \mathrm{ml} / \mathrm{g} \\
3.6 \mathrm{ml} / \mathrm{g} \\
0.01 \mathrm{ml} / \mathrm{g}\end{array}$ & $\begin{array}{l}\text { Low } \\
\text { High } \\
\text { Medium } \\
\text { Medium } \\
\text { Low }\end{array}$ & $\begin{array}{l}\text { Low } \\
\text { High } \\
\text { High } \\
\text { High } \\
\text { Low }\end{array}$ & $\begin{array}{l}\text { Low } \\
\text { High } \\
\text { Medium } \\
\text { Medium } \\
\text { Low }\end{array}$ \\
\hline $\begin{array}{l}\text { Radioactive half-life } \\
\text { Tritium } \\
\text { Uranium } \\
\text { Strontium-90 } \\
\text { Iodine-129 } \\
\text { Nitrate } \\
\end{array}$ & $\begin{array}{l}12.3 \mathrm{yr} \\
\text { assumed inf. } \\
28.8 \mathrm{yr} \\
\text { assumed inf. } \\
\text { N/A }\end{array}$ & $\begin{array}{l}\text { Low } \\
\text { Low } \\
\text { Low } \\
\text { Low }\end{array}$ & $\begin{array}{l}\text { High } \\
\text { Low } \\
\text { High } \\
\text { Low }\end{array}$ & $\begin{array}{l}\text { Low } \\
\text { Low } \\
\text { Low } \\
\text { Low }\end{array}$ \\
\hline $\begin{array}{l}\text { Dispersivity } \\
\text { Longitudinal } \\
\text { Transverse horizontal } \\
\text { Transverse vertical } \\
\end{array}$ & $\begin{array}{l}30 \mathrm{ft} \\
5 \mathrm{ft} \\
0.1 \mathrm{ft}\end{array}$ & $\begin{array}{l}\text { Medium } \\
\text { Medium } \\
\text { Medium } \\
\end{array}$ & $\begin{array}{l}\text { Medium } \\
\text { Medium } \\
\text { Low }\end{array}$ & $\begin{array}{l}\text { Medium } \\
\text { Medium } \\
\text { Low }\end{array}$ \\
\hline Effective porosity & 0.30 & Medium & Medium & Medium \\
\hline Bulk density & $1.6 \mathrm{~g} / \mathrm{ml}$ & Low & Medium & Low \\
\hline
\end{tabular}

\subsection{Transport Model Results}

The plume maps based on recent FNB plume monitoring well data, define the initial conditions for transport simulation (Figures 11-15). These plan view maps were assumed to represent average contaminant concentration levels over a vertical region extending to $33^{\prime}$ below the water table. The maps were digitized using Earthvision ${ }^{\circledR}$ software. Well average concentrations were computed at the plume wells and the Compliance Boundary Wells (CBW). For each contaminant, predicted concentration is compared to their MCL. Each simulation was continued until peak concentration was observed in the compliance boundary wells. Groundwater transport times between the basin and the compliance boundary are on the order of 10 to 12 years. For each contaminant, concentration breakthrough curves at the CBWs and plume contour plots in plan and cross-sectional views at key times are illustrated in Figures 16 - 35. Concentration levels presented in the breakthrough plots represent average concentration over well screens. Concentration levels presented in the plan view plots represent average concentration for the entire thickness of the "lower" aquifer zone ( $\left.\mathrm{IIB}_{1}\right)$. Concentration levels presented in the cross-sectional view plots represent local concentration. A discussion for each constituent follows.

\subsubsection{Tritium}

The tritium inventory in the initial plume is about 4 Curies (Ci). Tritium is essentially unretarded (retardation coefficient, $\mathrm{R}=1.005$ ). Therefore, the center of mass of the initial plume is expected to reach the compliance boundary in about 10 years. With a 
radioactive half-life of 12.3 years (Table $4-1$ ), half the plume activity will decay in transit. Wells FNB 2, 3, and 5 are currently above the $20 \mathrm{pCi} / \mathrm{ml} \mathrm{MCL}$ for tritium. In the assumed absence of a source term, these 3 wells are predicted to fall below $20 \mathrm{pCi} / \mathrm{ml}$ in approximately two to four years (Figure 16). Figure 17 illustrates tritium break-through at the CBWs. A maximum value of $7.0 \mathrm{pCi} / \mathrm{ml}$ (which is well below the MCL) is predicted to occur in CBW $2 \mathrm{c}$ after 8.5 years. From that point on there is a steady. decline in tritium values at $\mathrm{CBW} 2 \mathrm{c}$ with values below $1 \mathrm{pCi} / \mathrm{ml}$ within 20 years. Figures 18 and 19 illustrate plan and cross-sectional views of the plume at $2,4,6$, and 8 years into the future. The eight year future prediction of tritium on the two illustrations corresponds approximately with the maximum tritium value of $7 \mathrm{pCi} / \mathrm{ml}$ predicted at the $\mathrm{CBW} 2 \mathrm{c}$ (Figures 16 and 17). The MCL of $20 \mathrm{pCi} / \mathrm{ml}$ for tritium is predicted never to be exceeded at the compliance boundary.

\subsubsection{Nitrate}

The nitrate inventory in the initial plume is about $460 \mathrm{~kg}$. Like tritium, nitrate is essentially unretarded (retardation coefficient, $R=1.05$ ) and the plume center of mass is expected to reach the compliance boundary in about 10 years. Wells FNB 2 and 5 are currently above the $10 \mathrm{mg} / \mathrm{l} \mathrm{MCL}$ for nitrate. In the assumed absence of a source term, these 2 wells are predicted to fall below the MCL in approximately $1-2$ years (Figure 20). Figure 21 illustrates nitrate break-through at the compliance boundary wells. A maximum value of $1.2 \mathrm{mg} / \mathrm{l}$ (which is well below the MCL) is predicted to occur in CBW $2 \mathrm{c}$ and $2 \mathrm{~d}$ after 10 years. In approximately 20 years it is predicted that only a trace of nitrate will be present at the CBWs. Figures 22 and 23 illustrate plan and cross-sectional views of the plume at $2,4,6$, and 8 years into the future. The MCL of $10 \mathrm{mg} / \mathrm{l}$ for nitrate is predicted never to be exceeded at the compliance boundary.

\subsubsection{Iodine-129}

The iodine- 129 inventory in the initial plume is about $0.006 \mathrm{Ci}$. The retardation factor (R) for iodine-129 is 20 based on the $K_{d}$ value given in Table 4-1. The center of mass of the plume is therefore expected to reach the compliance boundary in about 200 years. Radioactive decay is neglected because the half-life of iodine-129 is large compared to the transport times. Wells FNB 2 and 5 are currently above the $1 \mathrm{pCi} / \mathrm{MCL}$ for iodine129. In the assumed absence of a source term, the plume wells are predicted to fall below the MCL within 90 to 100 years (Figure 24). Figure 25 illustrates iodine-129 breakthrough at the compliance boundary wells. A maximum value of $1.1 \mathrm{pCi} / 1$ is predicted to occur in CBW $2 \mathrm{~d}$ after 180 years. From that point on there is a steady decline in iodine129 values at CBW 2d. Figures 26 and 27 illustrate plan and cross-sectional views of the plume at 50,100,200, and 300 years into the future. CBW 2d is the only compliance well predicted to exceed the current MCL in 180 years. The remaining CBWs are all well below the MCL. 


\subsubsection{Strontium-90}

The strontium-90 inventory in the initial plume is about $0.028 \mathrm{Ci}$. The retardation factor (R) for strontium-90 is 17 based on the $K_{d}$ value given in Table 4-1. The center of mass of the plume is therefore predicted to reach the compliance boundary in 170 years. However, with a radioactive half-life of 28.8 years (Table $4-1$ ), virtually all the plume activity will decay in transit. Wells FNB 2,3 and 5 are currently above the $8 \mathrm{pCi} / 1 \mathrm{MCL}$ for strontium-90. In the assumed absence of a source term, these wells are predicted to fall below the MCL after 20 to 40 years (Figure 28). Figure 29 illustrates strontium-90 break-through at the compliance boundary wells. A maximum value of $0.23 \mathrm{pCi} / 1$ is predicted to occur in $\mathrm{CBW} 2 \mathrm{c}$ after 110 years. From that point on there is a steady decline in strontium-90 values at CBW 2c. Figures 30 and 31 illustrate plan and crosssectional views of the plume at $50,100,150$, and 200 years into the future. Strontium-90 concentrations are not predicted to exceed the MCL at the compliance boundary nor even reach the compliance boundary.

\subsubsection{Uranium (Total)}

The total uranium inventory in the initial plume is about $52 \mathrm{~kg}$. The retardation factor (R) for uranium is 22 based on the $K_{d}$ value given in Table 4-1. The center of mass of the plume is therefore expected to reach the compliance boundary in about 220 years. Radioactive decay is neglected because the half-lives of uranium isotopes are large compared to the transport times. Wells FNB 2 and 5 are currently above the $20 \mu \mathrm{g} / 1$ MCL for uranium. In the assumed absence of a source term, these wells are predicted to fall below the MCL after 60 to 70 years (Figure 32). Figure 33 illustrates uranium breakthrough at the compliance boundary wells. A maximum value of $5.0 \mu \mathrm{g} / 1$ is predicted to occur in CBW $2 d$ after 240 years, which is well below the MCL. Figures 34 and 35 illustrate plan and cross-sectional views of the plume at 50, 150, 250, and 350 years into the future. At no time does predicted total uranium concentration exceed the MCL at the compliance boundary.

\subsection{Quantitative uncertainty analysis}

Additional numerical simulations were performed to quantify the uncertainty in the nominal break-through curve results for compliance boundary well with the largest peak concentration (CBW $2 \mathrm{c}$ or $2 \mathrm{~d}$ depending on contaminant). Three settings for dispersivity were considered (Table 4-2). The nominal settings are also shown for comparison in the table. 
Table 4-2: Dispersivity values considered in sensitivity analysis

\begin{tabular}{|l|l|l|l|l|}
\hline Case & $\begin{array}{l}\text { Longitudinal } \\
\text { dispersivity }(\mathrm{ft})\end{array}$ & $\begin{array}{l}\text { Transverse } \\
\text { horizontal } \\
\text { dispersivity }(\mathrm{ft})\end{array}$ & $\begin{array}{l}\text { Transverse } \\
\text { vertical } \\
\text { dispersivity }(\mathrm{ft})\end{array}$ & Comments \\
\hline 1 & 10 & 1 & 0.1 & $\begin{array}{l}\text { Minimum values that are } \\
\text { numerically feasible } \\
\text { (Peclet number = 10) }\end{array}$ \\
\hline (nominal) & 30 & 5 & 0.1 & Nominal setting \\
\hline 2 & 100 & 10 & 1 & Intermediate setting \\
\hline 3 & 280 & 28 & 2.8 & $\begin{array}{l}\text { Longitudinal value is 10\% total } \\
\text { travel length }\end{array}$ \\
\hline
\end{tabular}

Case 1 produces the minimum amount of plume dispersion or dilution that can be numerically simulated for the resolution of the OFASB mesh (100 ft). This case was run for all 5 contaminants. Case 3 corresponds to the rule of thumb that longitudinal dispersivity should be about $10 \%$ of plume length. This case is considered a conservative upper limit because smaller values should be used early in the transient while the plume is small. Also, numerical dispersion creates additional plume dilution. A larger dispersivity causes more plume dilution, but also transports contamination to the compliance boundary faster before radioactive decay further reduces plume strength. These competing effects are important for tritium and strontium-90, for which radioactive decay are considered, so case 3 was run for both. Total uranium, iodine- 129 and nitrate are modeled as having no decay, so case 3 would only result in a lower concentration at the compliance boundary and was not run. Case 2 is an intermediate setting run only for tritium and strontium-90.

For the porosity sensitivity analysis the low and high end member cases were analyzed. An effective porosity of $20 \%$ was considered for all 5 contaminants because this setting increases the pore velocity and decreases groundwater travel time. An effective porosity of $40 \%$ was also considered for total uranium, iodine-129 and nitrate. Strontium-90 was not considered because its nominal break-through curves is so far below MCL that changing porosity would not challenge the bottom-line outcome. Tritium was not considered because it is unretarded and has a short half-life. Increasing effective porosity for tritium would only result in a lower break-through concentration.

A $\mathrm{K}_{\mathrm{d}}$ value of $1 \mathrm{ml} / \mathrm{g}$ was considered for iodine-129 for the purpose of testing model sensitivity to $\mathrm{K}_{\mathrm{d}}$. This is the maximum value reported for typical aquifer conditions by Looney et al. (1987). Typical aquifer conditions generally include a $\mathrm{pH}$ significantly higher than that at the OFASB (i.e. $\mathrm{pH}=5$ rather than $\mathrm{pH}=4$ in OFASB core of plume). Thus, the maximum value reported by Looney et al. (1987) may be a reasonable minimum value for the OFASB. The nominal $K_{d}$ values for uranium, strontium-90, tritium, and nitrate already represent realistic lower bounds.

Figures 36 through 40 summarize the sensitivity results for all 5 contaminants. None of the sensitivity runs result in a large deviation from the nominal case. 


\subsection{Detailed Discussion of Geochemical Analysis}

The transport behavior of a dissolved constituent depends on the constituent, the groundwater composition, and the aquifer mineralogy. Site specific studies were used to estimate the water table aquifer mineralogy of the OFASB. The Geochemical Information Management System (GIMS) database was used to obtain an estimate of the groundwater composition. Where possible, site specific studies of individual constituent behavior were used to estimate $\mathrm{K}_{\mathrm{d}}$ values, with supporting evidence from other published studies. For constituents not covered in site specific studies, pertinent scientific literature was used to estimate $\mathrm{K}_{\mathrm{d}}$ values.

It must be noted that groundwater models using $\mathrm{K}_{\mathrm{d}}$ values provide only limited estimations of the transport behavior of dissolved constituents in groundwater. A $\mathrm{K}_{\mathrm{d}}$ value is a measure of the steady state partitioning of a constituent between the solid and aqueous phases. Most studies measure partitioning in a simple system consisting of one solid phase and one dissolved constituent with ionic strength variations achieved with relatively inert electrolytes. Such systems do not reflect the complexity of natural aquifer conditions. Aquifer solids are typically a blend of several different types of sorption surfaces and heterogeneities in the blend are common. In addition, the speciation of dissolved constituents can complicate transport behavior. Complexes that limit sorption are not considered in most measurements of $\mathrm{K}_{\mathrm{d}}$ values and variations in contaminant speciation during transport are rarely considered.

The spatial distribution of aquifer heterogeneities is also an important factor in contaminant transport. Sedimentation and diagenetic processes result in aquifer heterogeneities that are not randomly distributed. Thus, transport behavior of a constituent at two sites with the same degree of heterogeneity may be very different if the distribution of heterogeneities is different. For example, linear heterogeneities that trend transverse to groundwater flow may cause different transport behavior than if they trend in the direction of groundwater flow. Thus, models that randomly vary $\mathrm{K}_{\mathrm{d}}$ values and those that use $K_{d}$ values measured in-situ at a site cannot accurately describe transport behavior of a constituent without knowledge of the spatial distribution of aquifer heterogeneities.

Therefore, the $\mathrm{K}_{\mathrm{d}}$ values presented here are meant for use in estimating bounding conditions of contaminant transport rather than for use in models that attempt to accurately predict contaminant concentrations.

The retardation of most metals and radionuclides is strongly influenced by the mineralogy of the aquifer and the chemistry of the groundwater. Aquifer mineralogy is important because the surface properties of minerals control sorption of the contaminants and surface properties vary considerably among minerals. The chemistry of the groundwater is important because it determines the dominant species of contaminants present and influences the surface chemistry of the aquifer minerals. The estimates of $K_{d}$ values presented here attempt to account for these factors by reviewing studies that were performed under conditions pertinent to the OFASB. 
Groundwater chemistry data for the five monitoring wells at the OFASB were obtained from GIMS for the time period of first quarter 1994 through first quarter 1995. Table 4-3 shows the average $\mathrm{pH}$ and average concentrations of $\mathrm{Cl}^{-}$and $\mathrm{SO}_{4}{ }^{-2}$ in groundwater from these wells. The groundwater in the contaminant plume is acidic ( $\mathrm{pH}=3.98-4.15)$. As suggested in Looney et al. (1987) this will result in greater mobility for contaminants in cationic forms than would be predicted by the $\mathrm{K}_{\mathrm{d}}$ values reported in that document. Likewise, the transport of constituents in anionic species may be more attenuated under these acidic conditions. The groundwater chemistry suggests that the only constituent whose transport may be complicated by complexing is uranium. The dominant species of $\mathrm{U}(\mathrm{VI})$ will be $\mathrm{UO}_{2}{ }^{+2}$ unless dissolved phosphate is elevated in the groundwater. At phosphate concentrations greater than $0.1 \mathrm{mg} / 1$ anionic phosphate complexes may dominate the uranium speciation (Langmuir, 1978) altering the transport behavior of uranium.

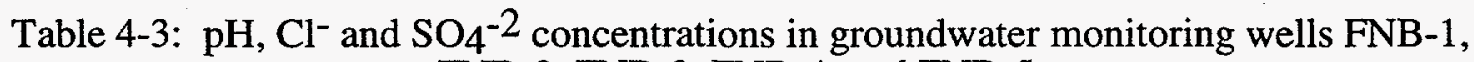
FNB-2, FNB-3, FNB-4, and FNB-5.

\begin{tabular}{|l|l|l|l|l|l|}
\hline & FNB-1 & FNB-2 & FNB-3 & FNB-4 & FNB-5 \\
\hline $\mathrm{pH}$ & 5.10 & 3.98 & 4.91 & 4.95 & 4.15 \\
\hline $\mathrm{Cl}^{-}(\mathrm{mg} / \mathrm{l})$ & 2.70 & 2.46 & 2.57 & 2.13 & 2.16 \\
\hline $\left.\mathrm{SO}_{4}^{-2}(\mathrm{mg} /)\right)$ & $<1$ & $<1.11$ & $<1$ & $<1$ & $<1.01$ \\
\hline
\end{tabular}

The dominant sorptive surfaces present in the soils of the OFASB are likely to be kaolinite and ferric iron oxyhydroxides (e.g. goethite). These minerals are common in the subsurface soils throughout the SRS area. Moreover, Ryan (1982) reported that the clay fractions of soil samples from the adjacent Mixed Waste Management Facility were dominated by kaolinite with traces of smectite and "fairly consistent percentages of iron on the clays".

Table 4-4 shows the recommended $\mathrm{K}_{\mathrm{d}}$ values for the five selected constituents at a groundwater $\mathrm{pH}$ of 4 . Following Table $4-4$ is a discussion of each constituent that summarizes the literature reviewed and the choice of recommended values. The general method of choosing $\mathrm{K}_{\mathrm{d}}$ values was that site specific studies took precedence over nonSRS studies. 
Table 4-4: Recommended $\mathrm{K}_{d}$ values for selected constituents at the OFASB in groundwater of $\mathrm{pH}=4$.

\begin{tabular}{|l|l|}
\hline Constituent & $\mathrm{K}_{\mathrm{d}}$ Value $(\mathrm{ml} / \mathrm{g})$ \\
\hline Tritium & 0.001 \\
\hline Nitrate & 0.01 \\
\hline Iodine-129 & 3.6 \\
\hline Strontium-90 & 3 \\
\hline Uranium (total) & 4 \\
\hline
\end{tabular}

\subsubsection{Tritium}

Tritium in groundwater is predominantly in the form of water and is virtually unretarded during groundwater flow. The value used in this model $(0.001 \mathrm{ml} / \mathrm{g})$ is that reported by Looney et al. (1987).

\subsubsection{Nitrate}

Nitrate is an anionic species and may be adsorbed by soils under acidic conditions ( $\mathrm{Li}$ et al., 1995; Bellini et al., 1996). However, in groundwater associated with the F-Area Seepage Basins nitrate concentrations show a linear trend with tritium concentrations (Figure 41). The trend dissipates at very high nitrate and tritium concentrations. Groundwater with these concentrations also tends to be the most acidic, and thus under these conditions some nitrate retardation is apparent. However, because of the strong linear trend between tritium and nitrate and the fact that nitrate from F- and H-Area Seepage Basins has reached the seepline along Four Mile Branch (Haselow et al., 1990), it is assumed here that nitrate is slightly retarded relative to tritium. Thus, a $K_{d}$ value of $0.01 \mathrm{ml} / \mathrm{g}$ was chosen.

\subsubsection{Iodine-129}

The dominant species of iodine-129 in the groundwater is iodide. Thus some retardation may be expected. The $\mathrm{K}_{\mathrm{d}}$ value chosen here $(3.6 \mathrm{ml} / \mathrm{g})$ is the minimum value measured in batch tests by Hoeffner (1985) using soils from the Savannah River Site. This value is consistent with those measured by Allard et al. (1980) for iodide sorption onto iron and aluminum hydroxides.

Analyses of four soil cores from within the OFASB suggest that significant retardation of iodine-129 has occurred. Based on these cores the average activity of iodine-129 in the soils beneath the basin was $4.07 \mathrm{pCi} / \mathrm{g}$ (WSRC, 1995). From this activity and the area of the basin it is estimated that approximately $0.07 \mathrm{Ci}$ remain in the top 2 meters of these soils. If this estimate is an order of magnitude high it still represents significant retardation of iodine-129, because only $0.006 \mathrm{Ci}$ are in the initial plume. Hence, a $\mathrm{K}_{\mathrm{d}}$ value of $3.6 \mathrm{ml} / \mathrm{g}$ is reasonable. 


\subsubsection{Strontium-90}

The work of Prout (1958) and Hoeffner (1985) demonstrate that strontium-90 transport is very sensitive to $\mathrm{pH}$. The $\mathrm{K}_{\mathrm{d}}$ value chosen here $(3 \mathrm{ml} / \mathrm{g})$ is from the $\mathrm{Kd}$ versus $\mathrm{pH}$ curve Hoeffner (1985) produced from batch sorption experiments.

\subsubsection{Uranium (Total)}

The uranium isotopes U-234, U-235, and U-238 behave the same during transport by groundwater. Ferric iron oxyhydroxides are among the strongest natural sorbents of uranium (Langmuir, 1978). Uranium sorption onto ferric iron oxyhydroxides is dependent on $\mathrm{pH}$ and weakens as $\mathrm{pH}$ drops below 5. Studies by Hsi and Langmuir (1985) and Waite et al. (1994) indicate that sorption decreases dramatically between $\mathrm{pH}$ of 4 and 5 depending on the concentration of uranium used, the amount of solid phase, and the nature of the solid phase. This suggests that in the $\mathrm{pH}$ range of OFASB groundwaters the $\mathrm{K}_{\mathrm{d}}$ value should be significantly less than that reported for more neutral $\mathrm{pH}$ by Looney et al. (1987). The $K_{d}$ value of $4 \mathrm{ml} / \mathrm{g}$ reported here is consistent with the studies referenced above.

The measurement of uranium transport in groundwater at SRS is complicated by the abundance of natural uranium in the aquifer sediments. The sandy aquifers contain uranium-bearing minerals such as apatite, monazite, crandallite, and sphene. These minerals can contain uranium in concentrations that exceed $100 \mathrm{ppm}$ and are soluble in acidic solutions. Thus, when an acidic plume migrates through these sands it will dissolve uranium-bearing minerals, increasing the concentration of uranium in the groundwater. In some cases reprecipitation of less soluble phases may then remove uranium from the groundwater as a co-precipitate. However, until further studies reveal the nature of these reactions in Savannah River Site sediments, modeling of uranium transport will remain tenuous. The most valid approach is to use a conservative $K_{d}$ value as a bounding condition so that the minimum reasonable retardation is achieved. This is the approach taken in this model.

\subsection{Flow Model Calibration Results}

For model calibration purposes, a contour plot of all available hydraulic head data from Upper Three Runs aquifer $\left(\mathrm{IB}_{1}\right.$ and $\mathrm{IIB}_{2}$ ) was prepared as shown in Figure 42. Data from monitoring wells, seepline surveys and cone penetrometer investigations were used to construct the map. OFASB model results for hydraulic head in the "lower" aquifer zone $\left(\mathrm{IIB}_{1}\right)$ are presented in Figure 43. The simulated water table is shown in Figure 44. Because Figure 42 is based on data from both aquifer zones (above and below the "tan clay"), the model results presented in Figures 43 and 44 should bracket the measured data. Overall, the agreement between the measured and simulated heads is good. Detailed head calibration results for OFASB model are presented below. 
Gordon Aquifer Unit Summary

rms of (FACT-data) differences:

avg of (FACT-data) differences:

avg of |FACT-data| differences:

max of (FACT-data) differences:

$\begin{array}{llllr}\text { Well } & \text { ID } & & \text { model-x } & \text { model-y } \\ \text { "FC } & \text { 1A " } & 7089.90 & 12409.76 \\ \text { "FC } & \text { 2B " } & 9434.23 & 12485.73 \\ \text { "FC } & \text { 2C " } & 9432.21 & 12493.79 \\ \text { "FC } & \text { 4C" } & 7324.74 & 15108.45 \\ \text { "FNB } & \text { 1A " } & 8136.07 & 13133.07 \\ \text { "FNB } & \text { 2A " } & 8139.19 & 13440.64 \\ \text { "FNB } & \text { 3A " } & 7883.91 & 13491.17\end{array}$

Lower Aquifer Zone Summary

rms of (FACT-data) differences:

avg of (FACT-data) differences:

avg of |FACT-data| differences:

max of \{FACT-data\} differences:

\begin{tabular}{|c|c|c|c|c|}
\hline Well & ID & & model-x & model-y \\
\hline "FBP & $3 \mathrm{~A}$ & $"$ & 4900.05 & 12122.59 \\
\hline "FBP & $7 D$ & $"$ & 4873.21 & 12082.94 \\
\hline "FBP & $8 D$ & $"$ & 5476.46 & 11685.78 \\
\hline " $F B P$ & $9 D$ & $"$ & 5114.07 & 11888.16 \\
\hline "FC & $1 B$ & $"$ & 7088.16 & 12417.46 \\
\hline "FC & 1C & " & 7086.65 & 12425.01 \\
\hline "FC & $4 \mathrm{E}$ & " & 7331.13 & 15123.61 \\
\hline "FNB & 1 & $"$ & 8119.87 & 13126.56 \\
\hline "FNB & 2 & " & 8147.93 & 13429.82 \\
\hline "FNB & 3 & " & 7874.20 & 13484.92 \\
\hline "FNB & 4 & $n$ & 7647.42 & 13290.21 \\
\hline "FNB & 5 & " & 8058.84 & 13527.23 \\
\hline "FNB & 6 & $"$ & 7808.88 & 13746.44 \\
\hline "FNB & 7 & " & 8140.50 & 13639.77 \\
\hline "FNB & 8 & " & 8315.60 & 13546.39 \\
\hline "NBG & 4 & . & 8427.66 & 11955.57 \\
\hline "NBG & 5 & 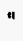 & 8609.72 & 11995.59 \\
\hline "ZW & 2 & " & 8120.06 & 13688.89 \\
\hline "FC & $2 \mathrm{D}$ & " & 9429.97 & 12500.98 \\
\hline " FC & $2 \mathrm{E}$ & " & 9428.91 & 12509.34 \\
\hline "FC & $2 F$ & " & 9426.60 & 12516.82 \\
\hline
\end{tabular}

Upper Aquifer Zone Summary

rms of (FACT-data) differences:

avg of (FACT-data) differences:

avg of |FACT-datal differences:

max of \{FACT-data\} differences:

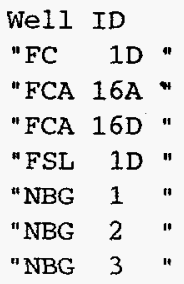

mode1-x

7084.36

7692.74

7840.35

7095.02

7913.10

8032.18

8172.79

12212.50

12032.73

11898.84

$$
\begin{array}{r}
0.970 \\
-0.623 \\
0.892 \\
-1.440
\end{array}
$$

zbot

96.7

78.8

129.5

116.3

107.9

111.1

109.2

ztop
101.7
83.8
134.5
121.3
117.9
121.1
119.2

head

data residual .

$\begin{array}{lll}143.5 & 143.8 & 0.3\end{array}$

$148.0 \quad 147.5 \quad-0.5$

$146.7 \quad 147.3 \quad 0.6$

$137.6 \quad 136.2 \quad-1.4$

$144.5 \quad 143.6 \quad-0.9$

$143.9 \quad 142.7 \quad-1.2$

$143.4 \quad 142.2 \quad-1.2$

$$
\begin{array}{r}
2.874 \\
1.372 \\
2.309 \\
-6.276
\end{array}
$$

zbot

141.0

183.2

172.8

177.9

151.8

183.9

176.4

177.2

180.8

182.1

179.6

193.5

200.2

192.0

195.0

196.1

194.9

194.8

159.2

188.9

207.3

ztop
171.0
203.2
192.8
197.9
156.8
188.9
181.4
207.2
210.8
212.1
209.6
203.5
210.2
202.0
205.0
227.5
226.4
204.8
164.2
193.9
212.3

head

194.2

194.7

207.4

200.6

210.8

214.0

185.2

210.5

206.8

209.0

213.2

207.1

209.4

205.3

203.8

217.0

217.7

207.3

208.3

209.4

216.1

$\begin{array}{lr}\text { data } & \text { residual } \\ 195.2 & 1.0 \\ 196.7 & 2.0 \\ 204.5 & -2.9 \\ 201.3 & 0.7 \\ 212.7 & 1.9 \\ 213.6 & -0.4 \\ 178.9 & -6.3 \\ 213.2 & 2.7 \\ 210.5 & 3.7 \\ 211.5 & 2.5 \\ 212.9 & -0.3 \\ 209.7 & 2.6 \\ 210.6 & 1.2 \\ 208.1 & 2.8 \\ 208.5 & 4.7 \\ 218.4 & 1.4 \\ 217.8 & 0.1 \\ 207.8 & 0.5 \\ 213.3 & 5.0 \\ 214.1 & 4.7 \\ 217.4 & 1.3\end{array}$

2.874

$-0.719$

2.233

5.240

zbot

217.2

215.1

221.1

208.5

200.9

203.6 ztop

222.2

235.1

241.1

228.6

232.3

233.6

233.5 head

223.6

225.2

225.0

224.4

224.4

224.8

217.6 data residual

$222.4-1.2$

$224.3-0.9$

$224.2 \quad-0.8$

$220.4 \quad-4.0$

$221.4 \quad-3.4$

$222.8 \quad 5.2$
$224.5 \quad 0.1$ 


\subsection{Summary}

Groundwater modeling was used to predict contaminant concentrations at the compliance boundary, which is down-gradient and within the path of groundwater flow. Because the plume concentrations have not been increasing and the selected remedial action for the surface units includes stabilizing and capping the residual contamination left in the soil, groundwater concentrations are expected to decrease to acceptable standards through natural attenuation. A groundwater flow and transport model was required to adequately demonstrate this expected decrease in concentrations. The groundwater flow and subsequent transport simulations provide predictions of the future groundwater contaminant levels to support the GWMZ.

Groundwater modeling was used to predict contaminant concentrations at the compliance boundary, which is down-gradient and within the path of groundwater flow. Predicted concentrations were compared to the maximum concentration limits (MCLs) for each constituent modeled. The plume concentrations at the OFASB have not been increasing. The selected remedial action for the surface units at the OFASB are stabilization and capping, therefore the residual contamination left in the soil, groundwater concentrations are expected to decrease to acceptable standards through natural attenuation. A groundwater flow and transport model was required to adequately demonstrate this expected decrease in concentrations.

Migration of tritium, nitrate, iodine-129, strontium-90, and total uranium from the OFASB to UTR was simulated using a three-dimensional, finite-element, fine-scale groundwater flow and solute contaminant transport model. The simulations were produced using an SRS/SRTC code called FACT. FACT (Hamm et al., 1997) has been designed to simulate isothermal groundwater flow, moisture movement, and solute transport in variably saturated and fully saturated subsurface media. The code is designed specifically to handle complex multi-layer and/or heterogeneous aquifer systems in an efficient manner and accommodates a wide range of boundary conditions. Since completion of the OFASB modeling effort the code has been verified and validated with a technically reviewed code manual (Hamm, et al., 1995).

The model boundaries cover the distance extending from about 1600' south (up-gradient) of the OFASB to Upper Three Runs, and several thousand feet east and west (Figure 3). Vertically, the model extends from ground surface to the bottom of the Gordon Aquifer Unit (Aquifer Unit IIA) (Figure 4). Predicted contaminant plumes are well within these boundaries.

Contaminant retardation due to geochemical effects was modeled using a constant distribution coefficient $\left(K_{d}\right)$ and conservative values. The initial plume configuration and concentration levels were defined from concentration contour maps. The vertical extent of contamination was assumed to be 33 feet below the water table (near the bottom of the screen zones in the monitoring wells and approximately half the aquifer thickness), Candidate compliance boundary wells were placed perpendicular to groundwater flow about 1600 feet up-gradient for the UTR. The screen zones of these compliance 
boundary wells is 40 feet in length, nearly fully penetrating. Plume migration was simulated from the present time through break-through at the compliance boundary.

Contamination migration simulations were performed for tritium, nitrate, iodine-129, strontium-90, and uranium. The results from the modeling demonstrated that concentrations of four of the five contaminants would meet existing MCLs at the compliance boundary, with only a slight exceedance of the iodine-129 MCL in one compliance boundary well. The model predicts that concentrations within the existing plume will fall below MCLs within 2 to 115 years. 


\subsection{References}

Allard, B., B. Torstenfelt, K. Anderson, and J. Rydberg, 1980, Possible retention of iodine in the ground, in Scientific Basis for Nuclear Waste Management, V. 2, C.J.M Northrup, Jr. (ed.), Plenum Press, p. 673-680.

Bellini, G., M.E. Sumner, D.E. Radcliffe, and N.P. Qafoku, 1996, Anion transport through columns of highly weathered acid soil: Adsorption and retardation, Soil Science Society of America Journal, v. 60, p. 132-137.

Flach, G. P., and Harris, M.K., 1997. Integrated Hydrogeological Model of the General Separations Area (U), Volume II: Groundwater Flow Model (U), WSRC-TR-960399, Westinghouse Savannah River Company, Aiken, SC, 118 pp.

Hamm, L. L., S. E. Aleman, W. F. Jones, G. P. Flach, J. S. Haselow, P. S. Huyakorn, S. Panday and T. Birdie, 1997, FACT: Subsurface flow and contaminant transport documentation and user's guide, WSRC-TR-95-223.

Haselow, J. S., M. Harris, B. B. Looney, N. V. Halverson, and J. B. Gladden, 1990, Analysis of soil and water at the Four Mile Creek seepline near the $\mathrm{F}$ and $\mathrm{H}$ area of SRS (U), WSRC-RP-90-0591.

Hoeffner, S.L., 1985, Factors that influence the pH in the SRP Burial Ground, DPST-85243, E.I du Pont de Nemours \& Co., Savannah River Laboratory, Aiken, SC.

Hsi, C.D. and D. Langmuir, 1985, Adsorption of uranyl onto ferric oxyhydroxides: Applications of the surface complexation site-binding model, Geochimica et Cosmochimica Acta, v. 49, p. 1931-1941.

Langmuir, D., 1978, Uranium solution-mineral equilibria at low temperatures with applications with applications to sedimentary ore deposits, Geochimica et Cosmochimica Acta, v. 42, p. 547-569.

Li, Y.C., A.K. Alva, D.V. Calvert, and D.J. Banks, 1995, Adsorption and transport of nitrate and bromide in a spodosol, Soil Science, v. 160, p. 400-404.

Looney, B. B., M. W. Grant, and C. M. King, 1987, Estimation of geochemical parameters for assessing subsurface transport at the Savannah River Plant, DPST85-904.

Prout, W. E., 1959, Adsorption of fission products by Savannah River Plant soil, DP394, E. I. du Pont de Nemours and Company, Aiken, SC.

Ryan, J.P., 1982, Batch and column strontium distribution coefficients with watersaturated soil strata from the Savannah River Plant Burial Ground, in Environmental Migration of Long-lived Radionuclides, International Atomic Energy Agency, Vienna. 
Smits, A. D., Harris, M. K., Hawkins, K. L., and Flach, G. P., 1997. Integrated Hydrogeological Model of the General Separations Area (U), Volume I: Hydrogeologic Framework (U), WSRC-TR-96-0399, Westinghouse Savannah River Company, Aiken, SC, 118 pp.

Waite, T.D., J.A. Davis, T.E. Payne, G.A. Waychunas, and N. Xu, 1994, Uranium (VI) adsorption to ferrihydrite: Application of a surface complexation model, Geochimica et Cosmochimica Acta, v. 58, p. 5465-5478.

WSRC (Westinghouse Savannah River Company) 1995. RCRA Facility Investigation/Remedial Investigation Report for the Old F-Area Seepage Basin (904-49G)(U), Rev. 1, WSRC-RP-94-942, June 1995.

WSRC (Westinghouse Savannah River Company), 1996. Corrective Measures Study/Feasibility Study for the Old F-Area Seepage Basin (904-49G) (U), Rev. 1, WSRC-RP-95-385, February, 1996. 


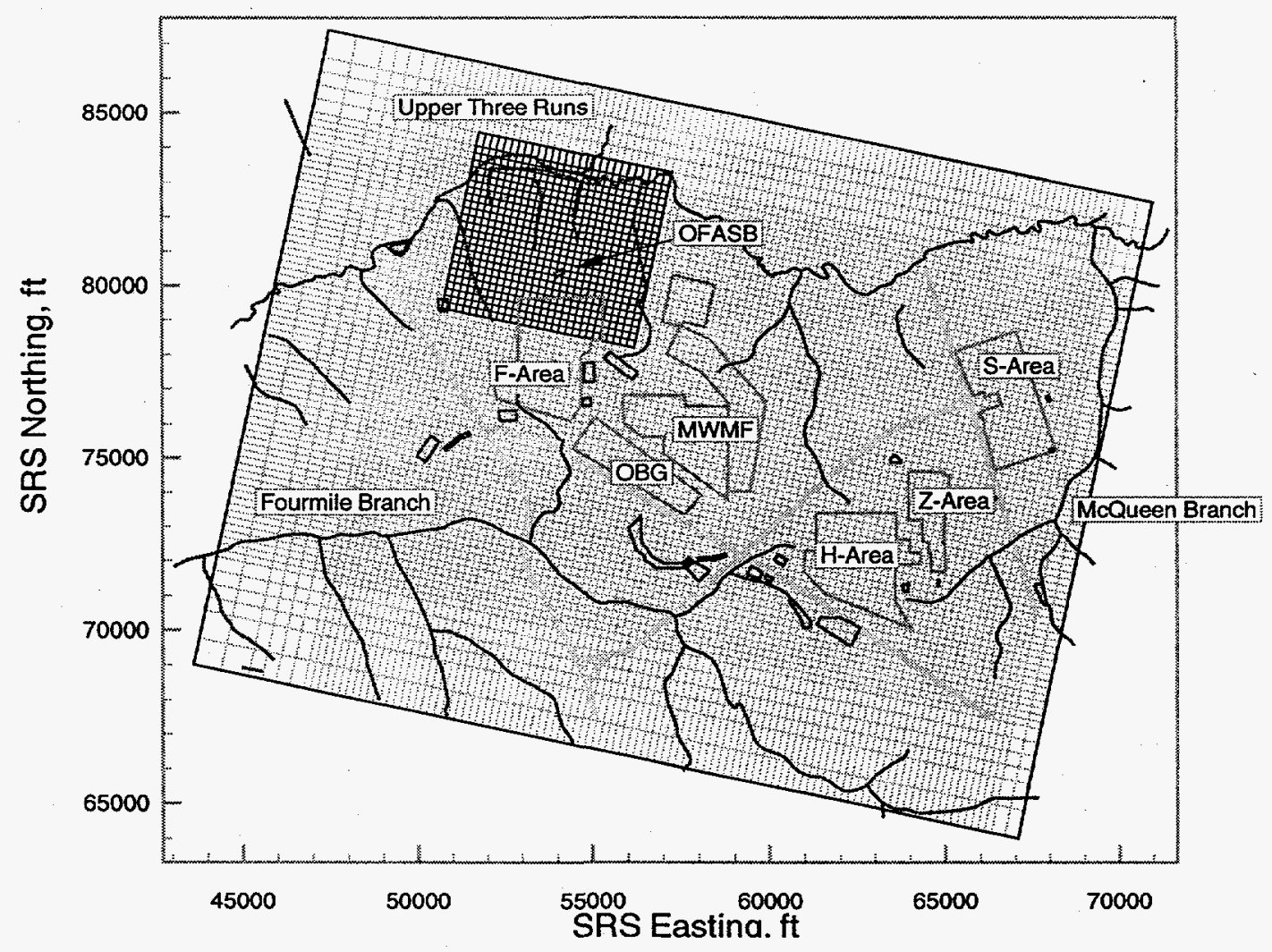

Figure 1: Areal footprints of the GSA flow model and the OFASB flow/transport model based on the FACT code. 


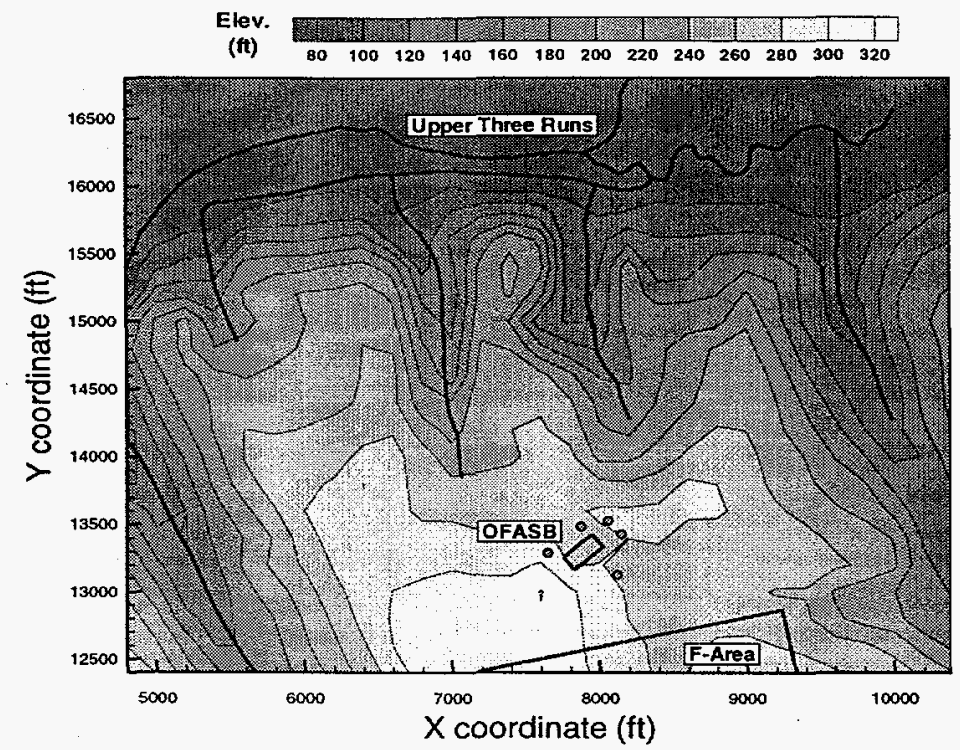

Figure 2: Topographic features near the Old F-Area Seepage Basin.

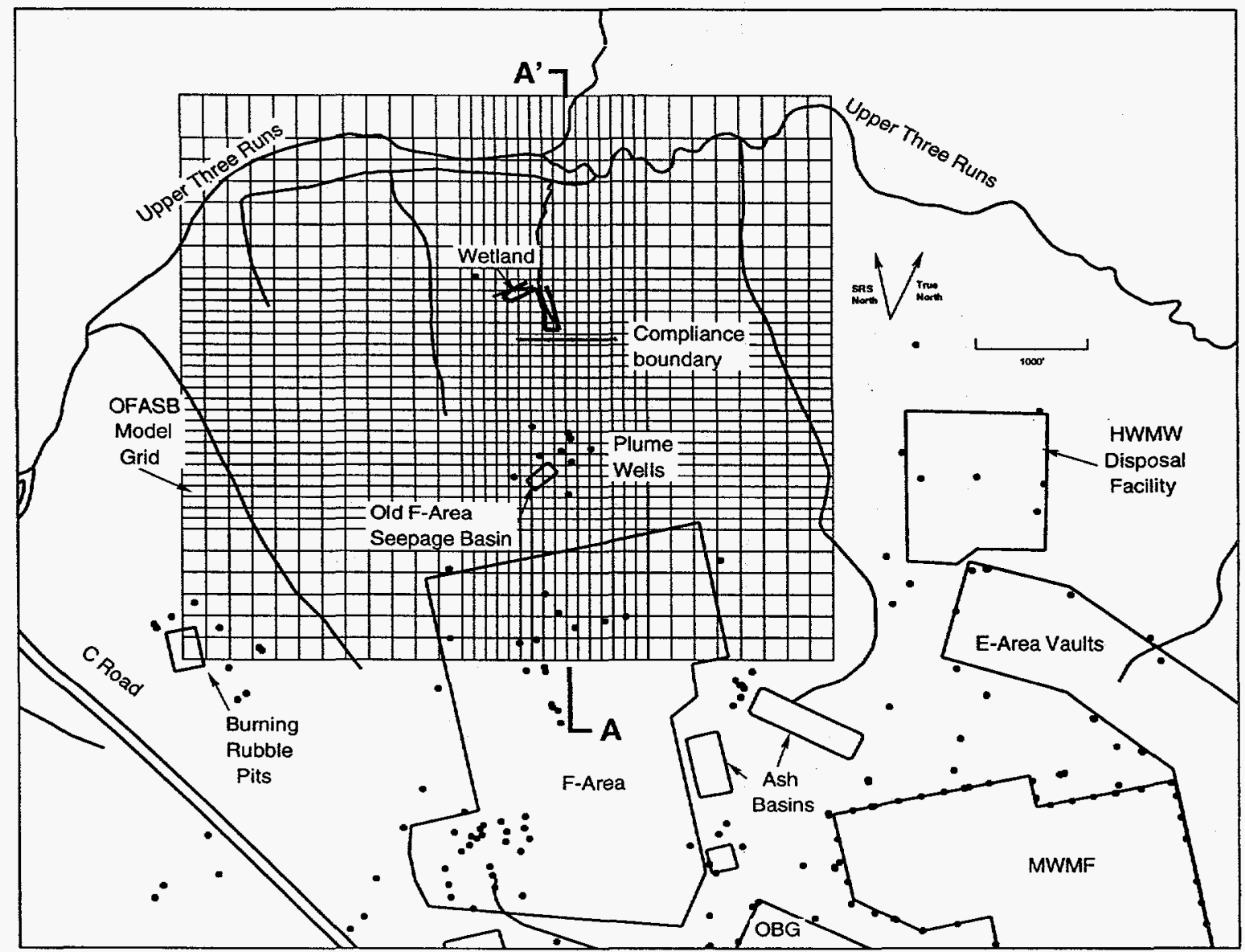

Figure 3: Location map of the Old F-Area Seepage Basin with monitoring wells, compliance boundary, and OFASB model grid. 


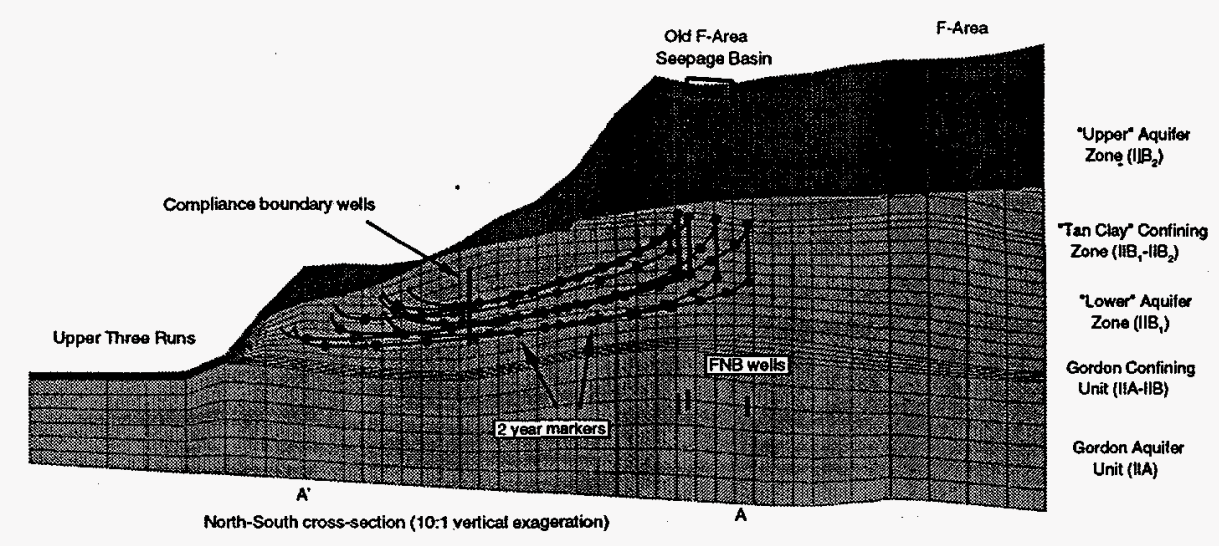

Figure 4: Simulated vertical groundwater flow paths starting from FNB well screens and hydrostratigraphic nomenclature for OFASB model.

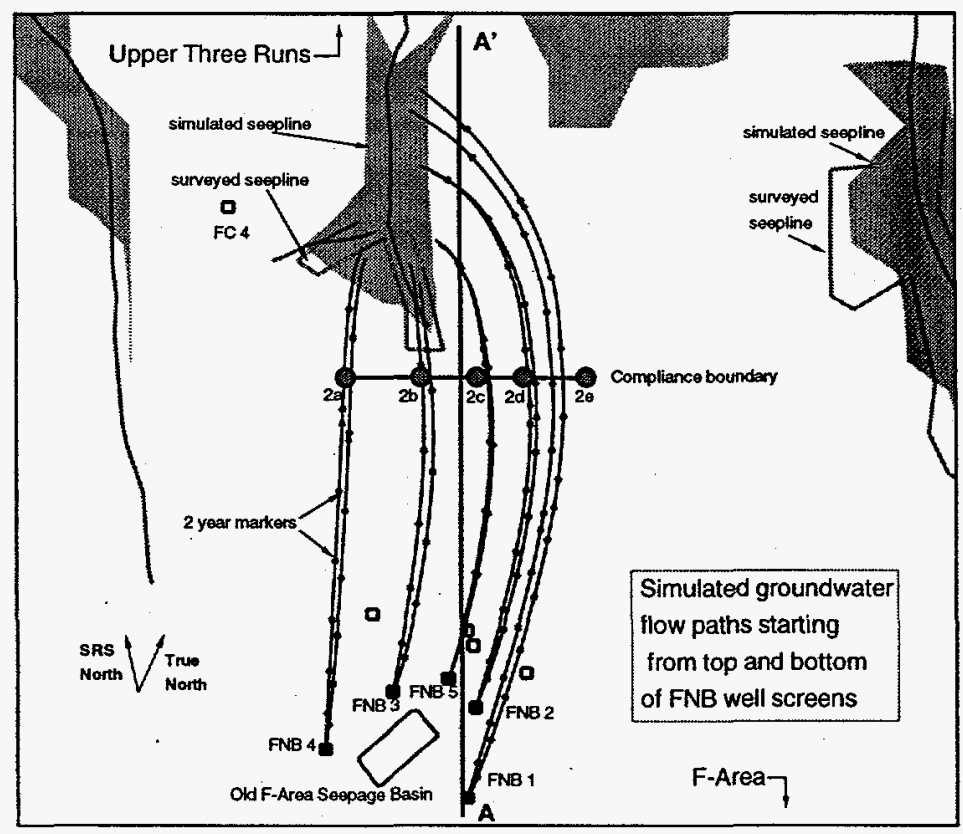

Figure 5: Simulated groundwater flow paths starting from the FNB well screens in the vicinity of OFASB along with simulated and surveyed seep lines. 


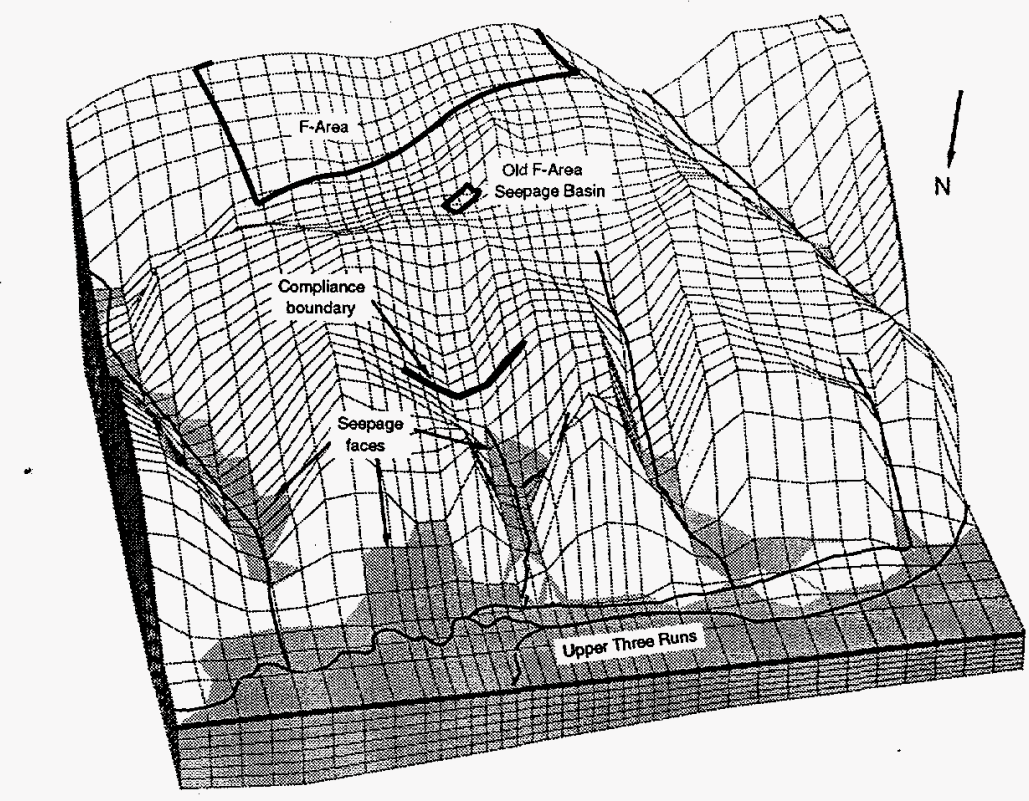

Figure 6: Simulated 3-D predicted saturated zones and seepage faces.

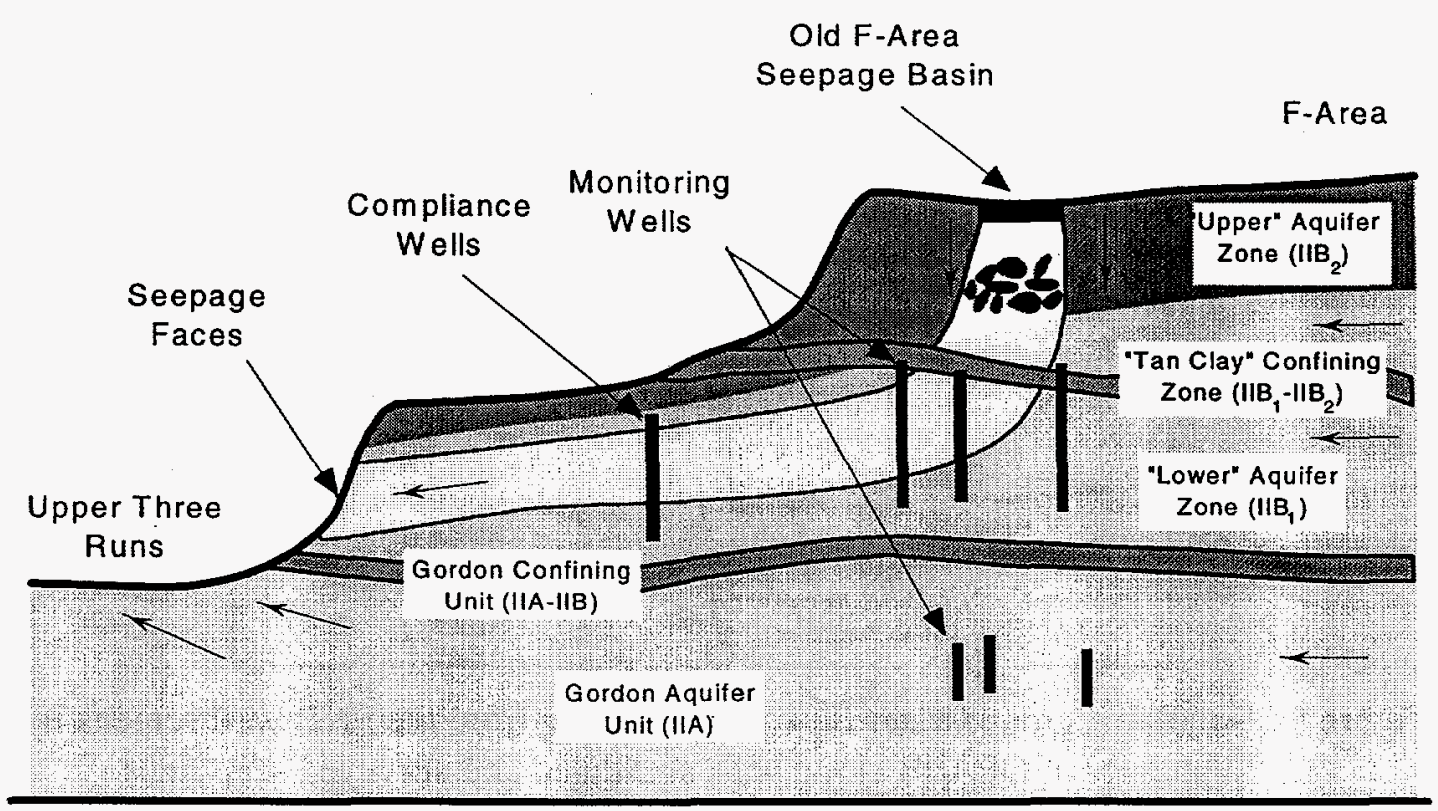

Figure 7: Conceptual model for species transport study near OFASB. 


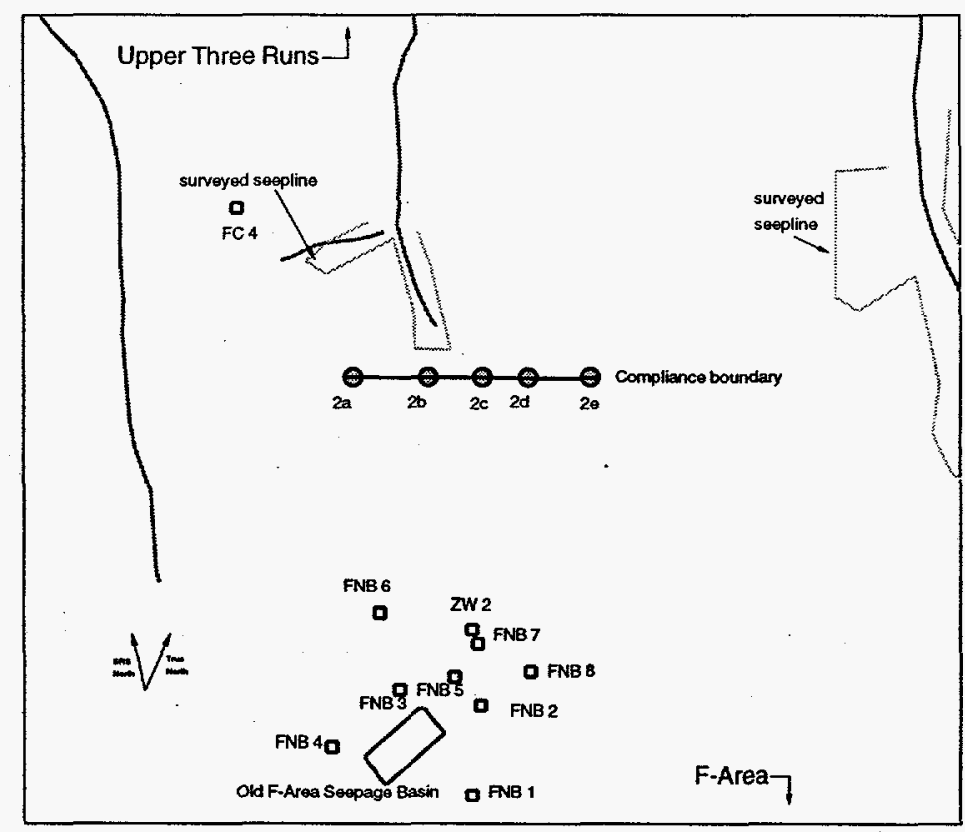

Figure 8: Close up showing the location of compliance boundary. 


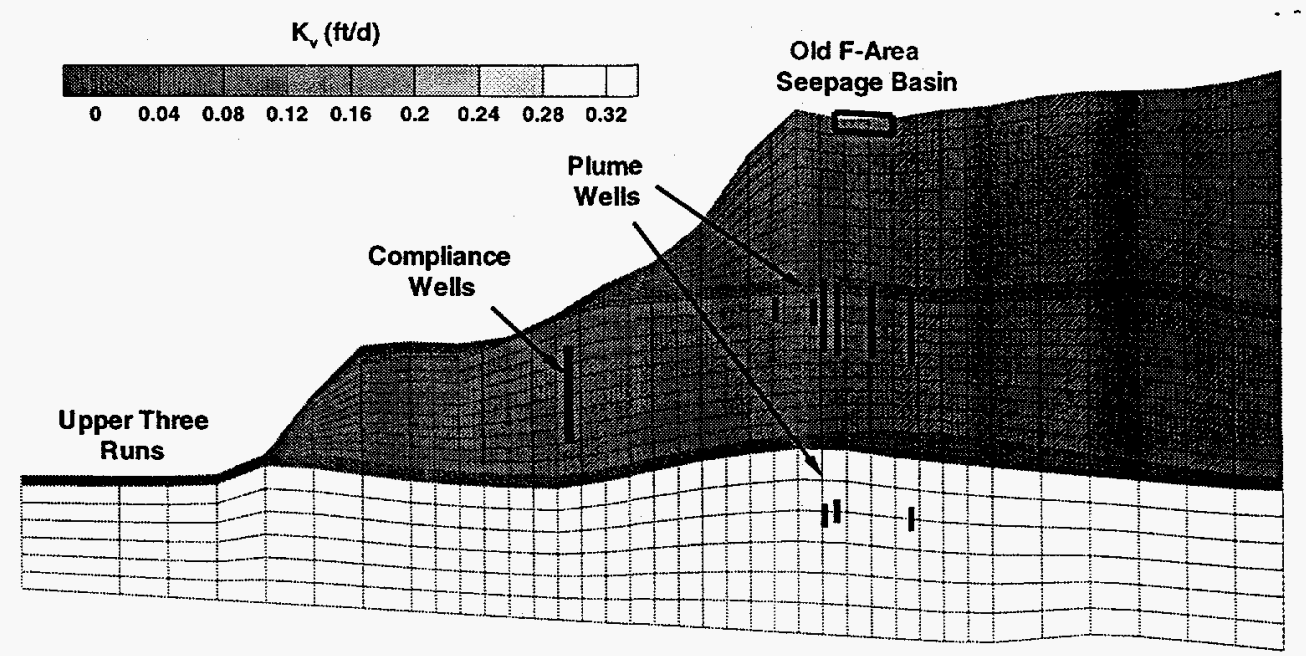

North-South Cross-Section (10:1 vertical exaggeration)

Figure 9: Vertical locations of plume and compliance wells in a North-South crosssection of OFASB model.

$K_{v}(t / d)$

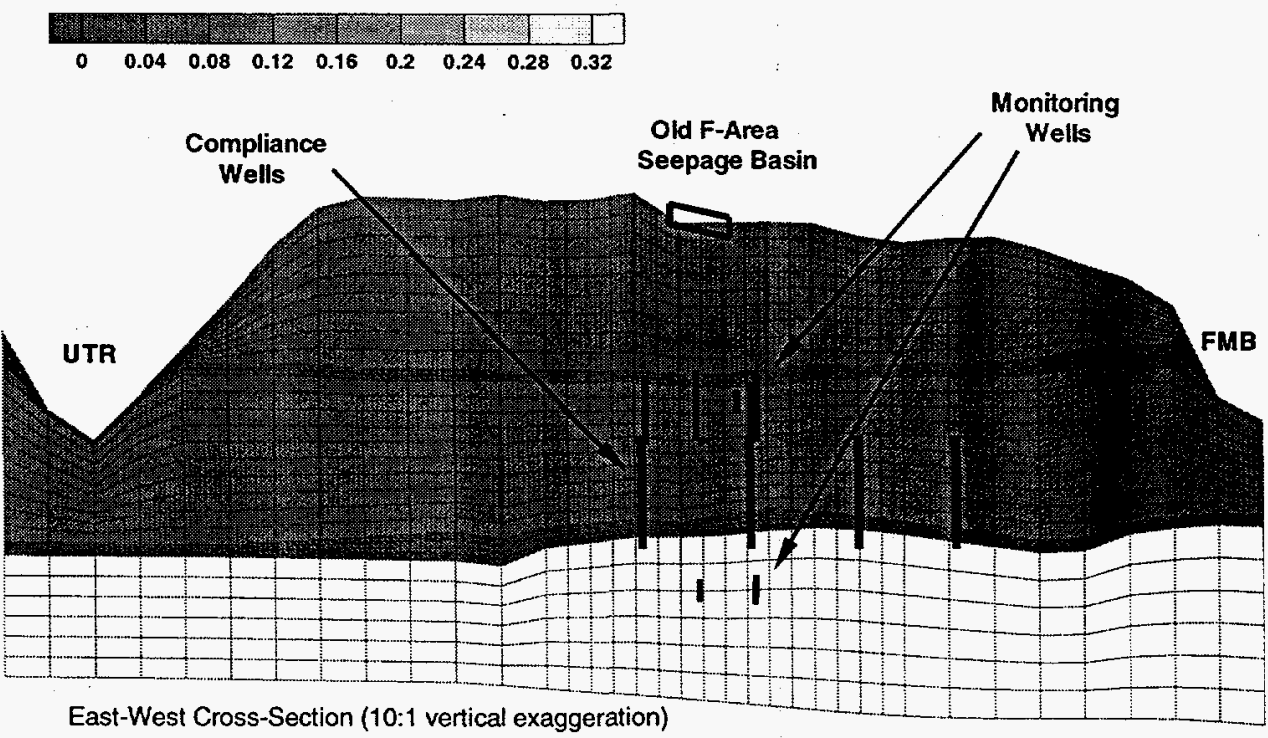

Figure 10: Vertical locations of plume and compliance wells in a East-West cross-section of OFASB model. 


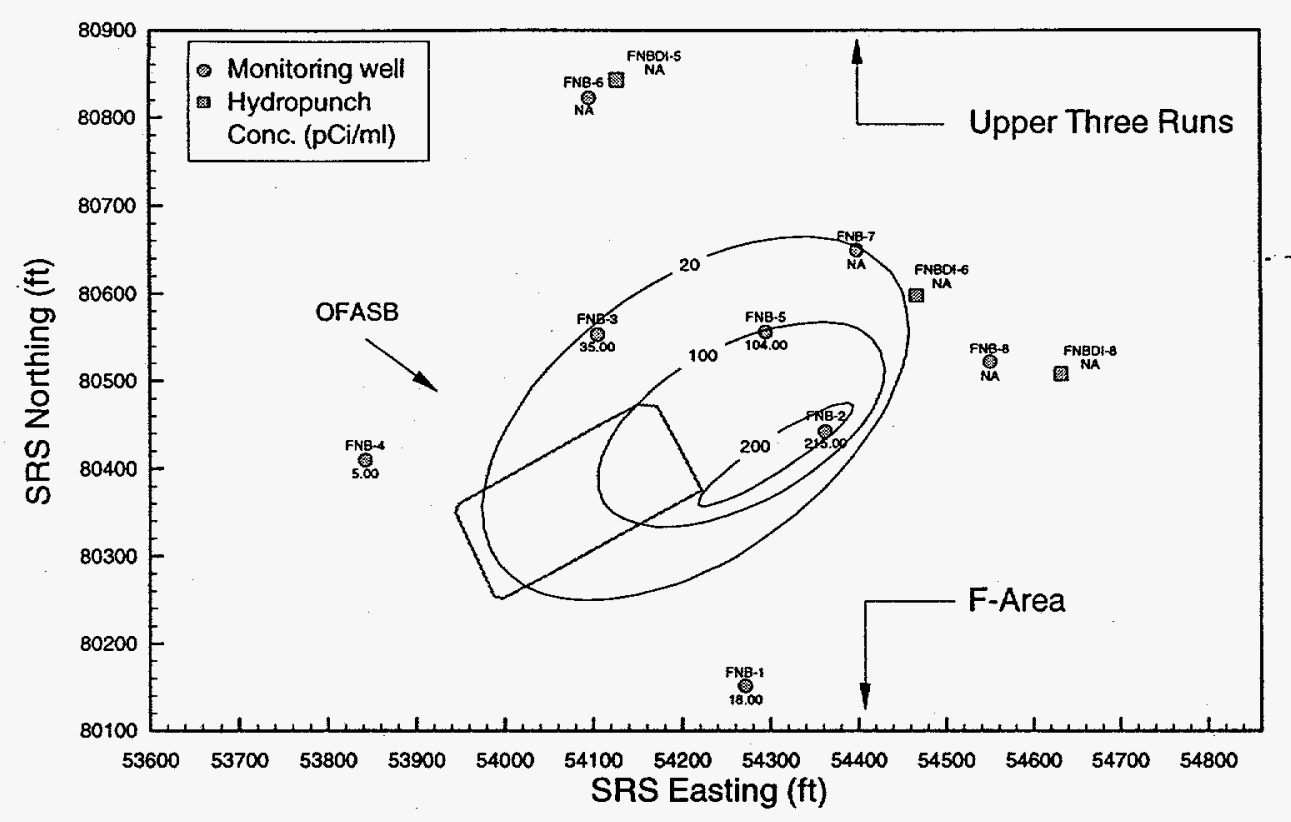

Figure 11: Initial concentration contours for Tritium.

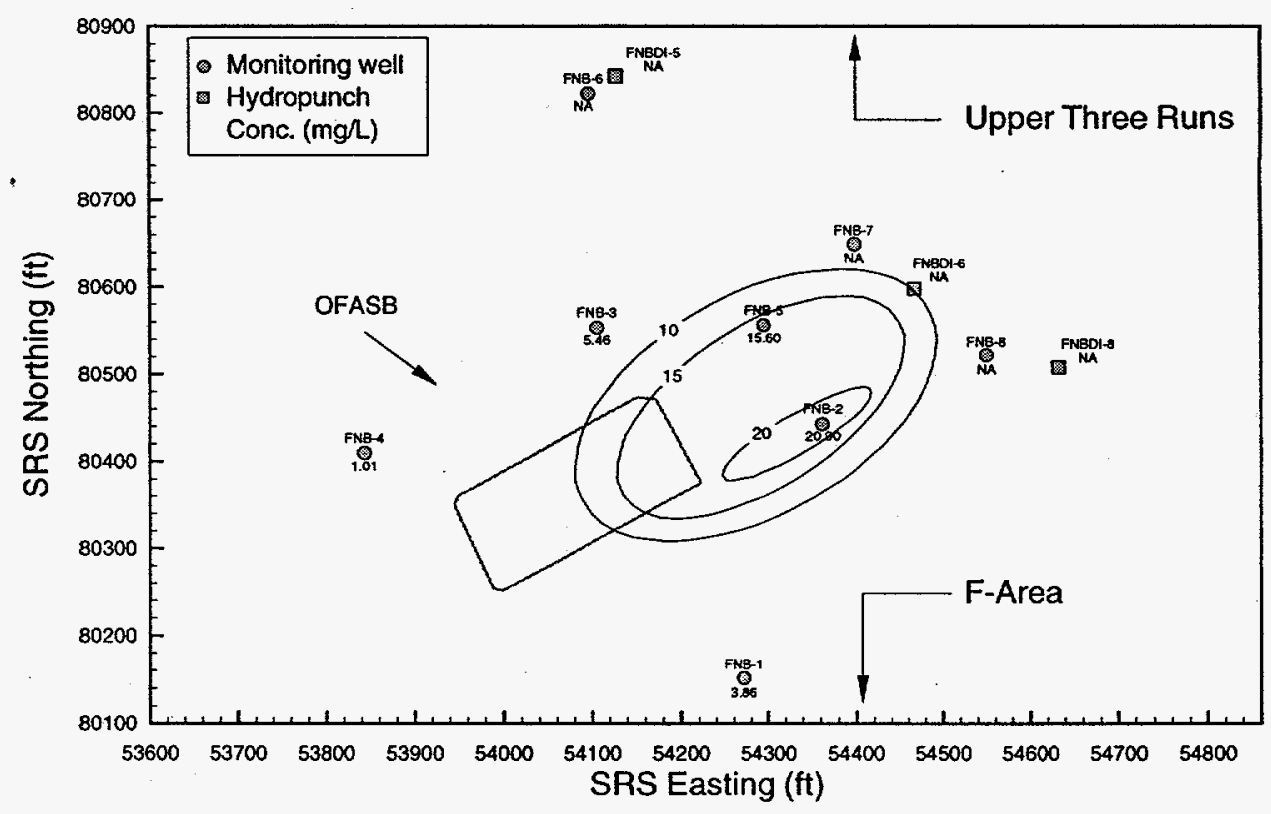

Figure 12: Initial concentration contours for Nitrate. 


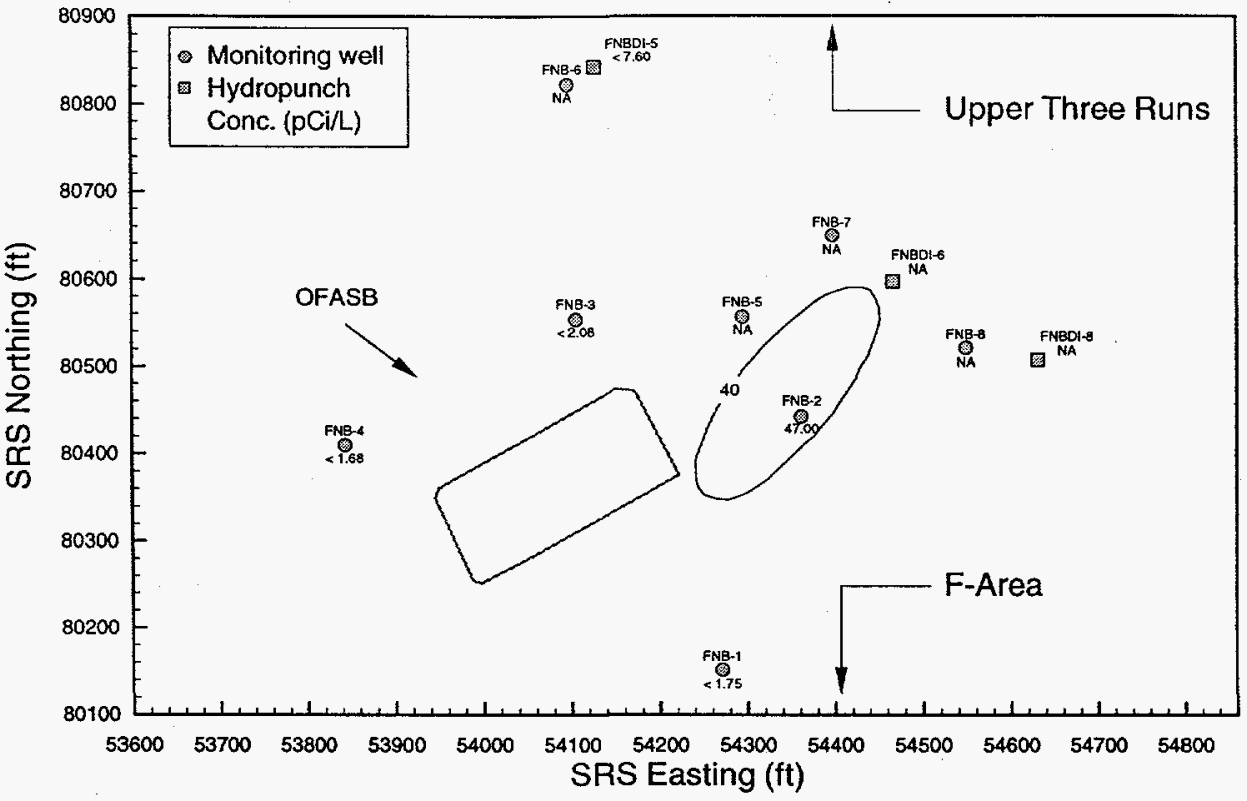

Figure 13: Initial concentration contours for Iodine-129.

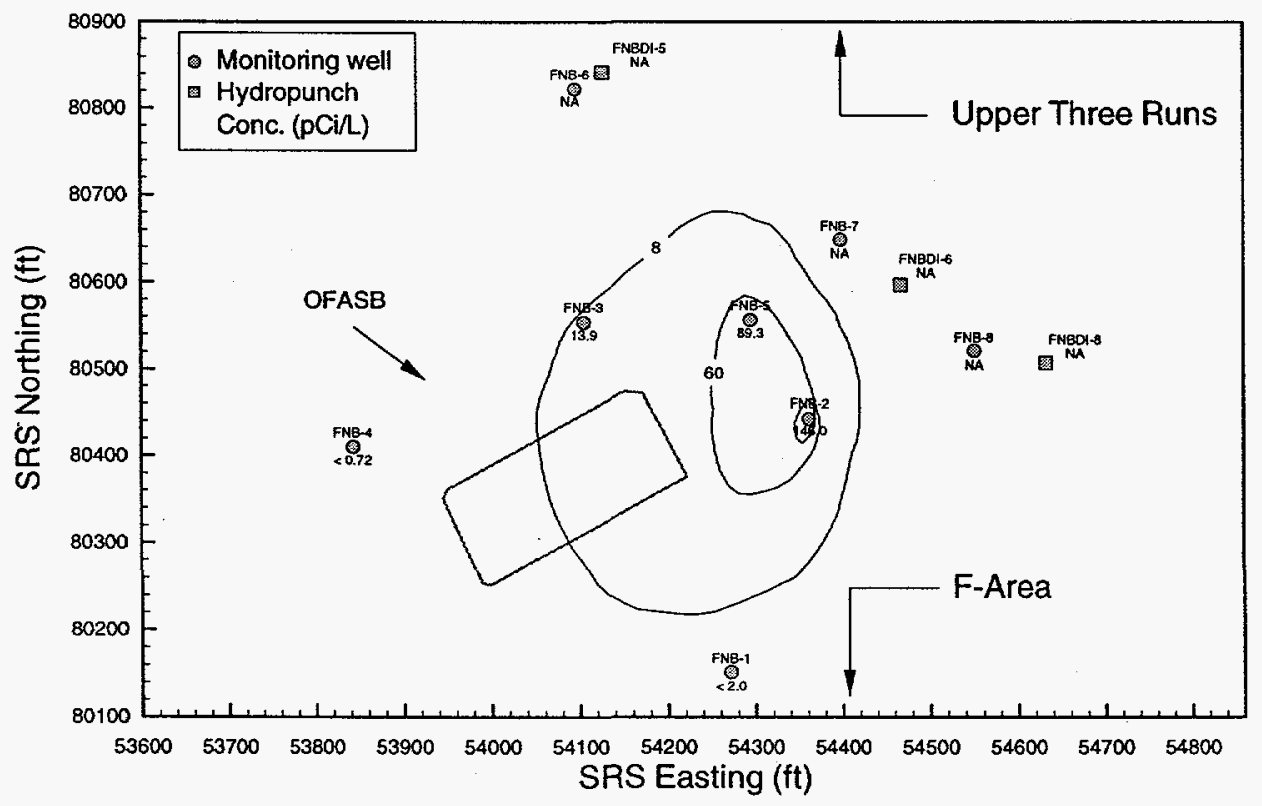

Figure 14: Initial concentration contours for Strontium-90. 


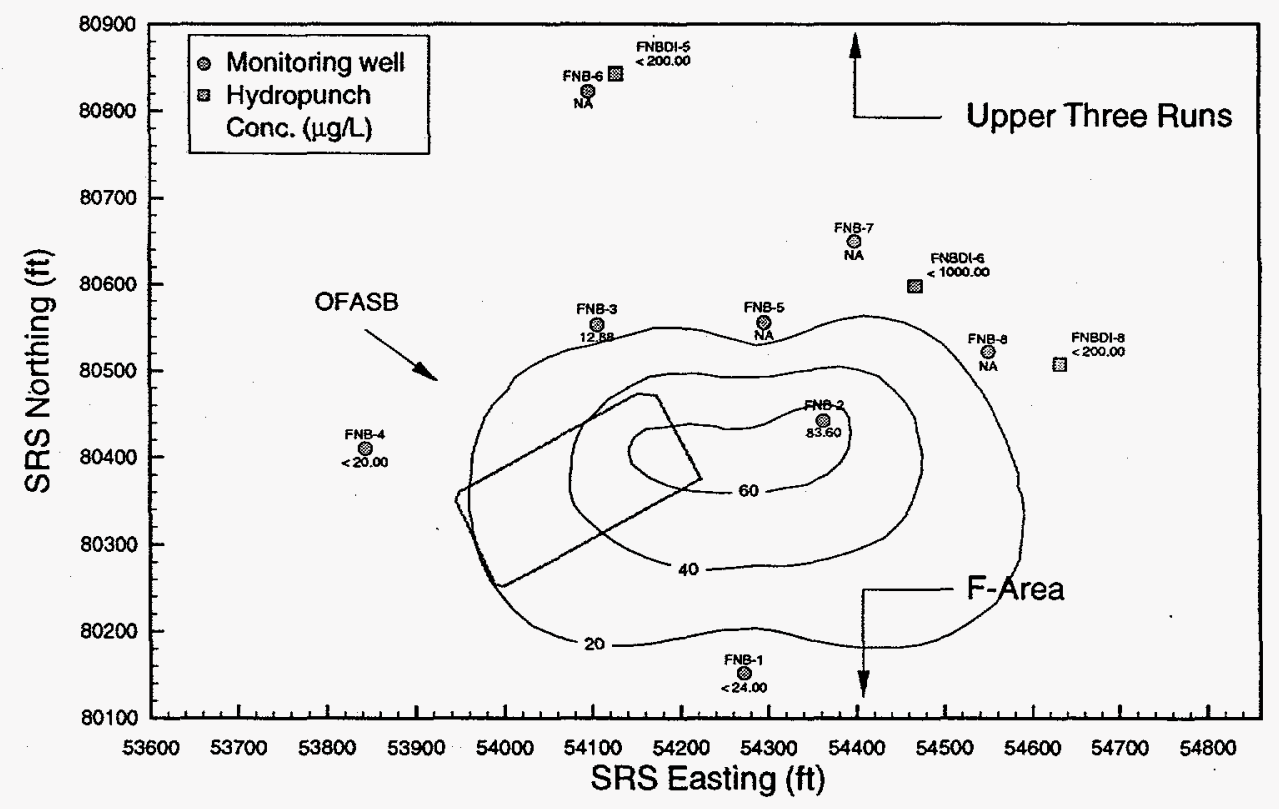

Figure 15: Initial concentration contours for total Uranium. 


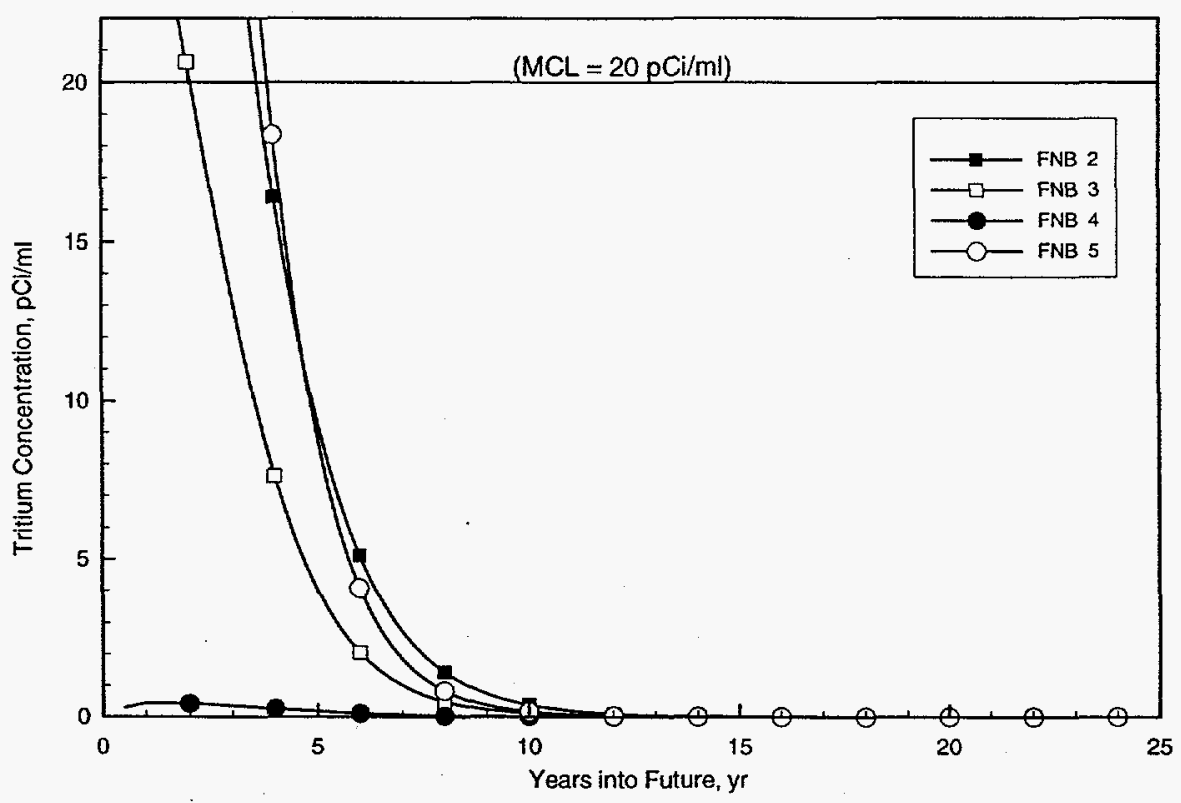

Figure 16: Predicted tritium concentration at FNB Point of Compliance wells.

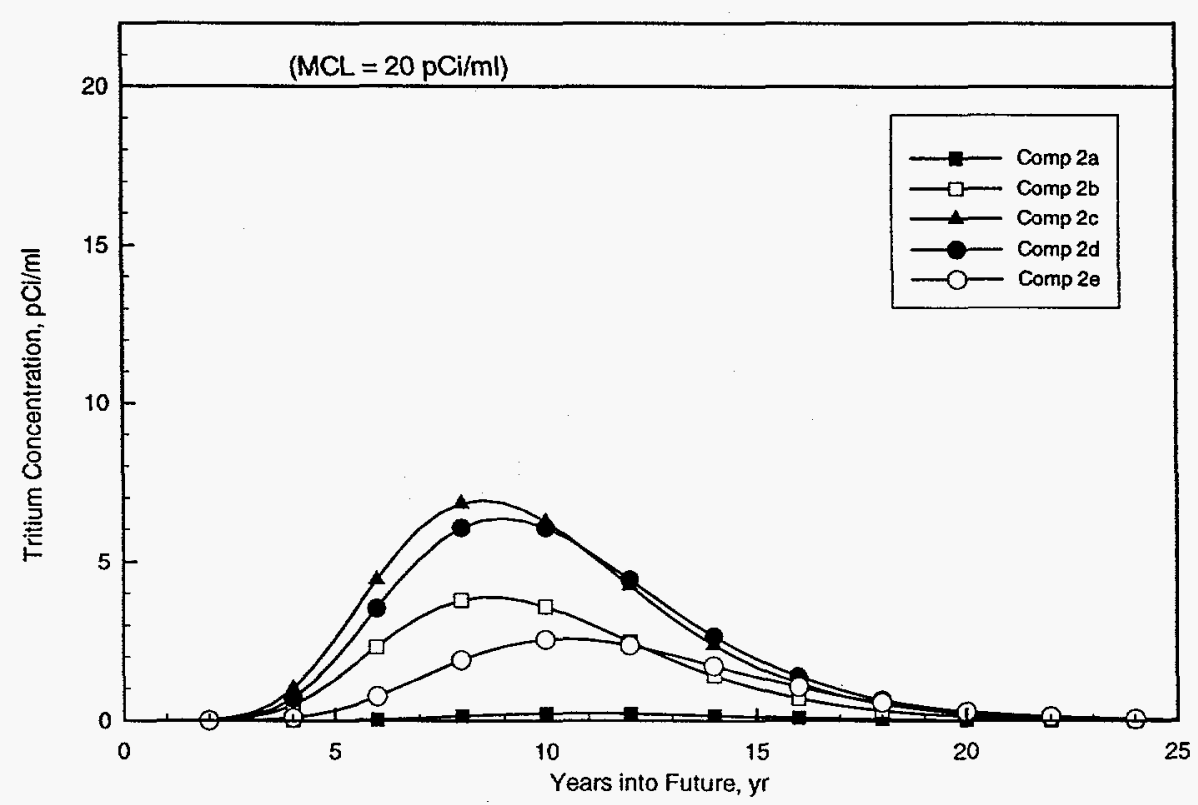

Figure 17: Predicted tritium concentration at Compliance Boundary. 

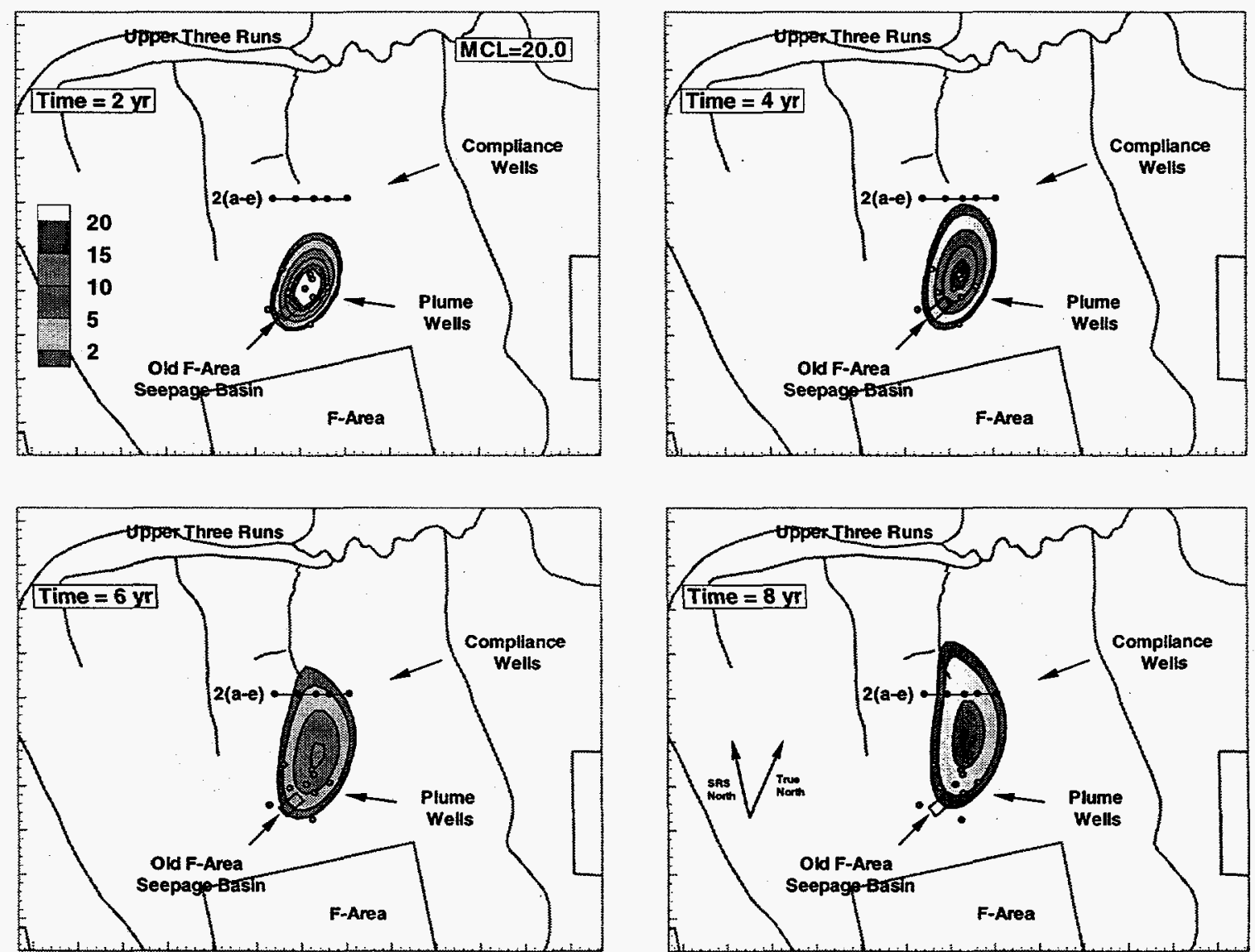

Figure 18: Predicted tritium plume conditions in two, four, six, and eight years (plan view). 

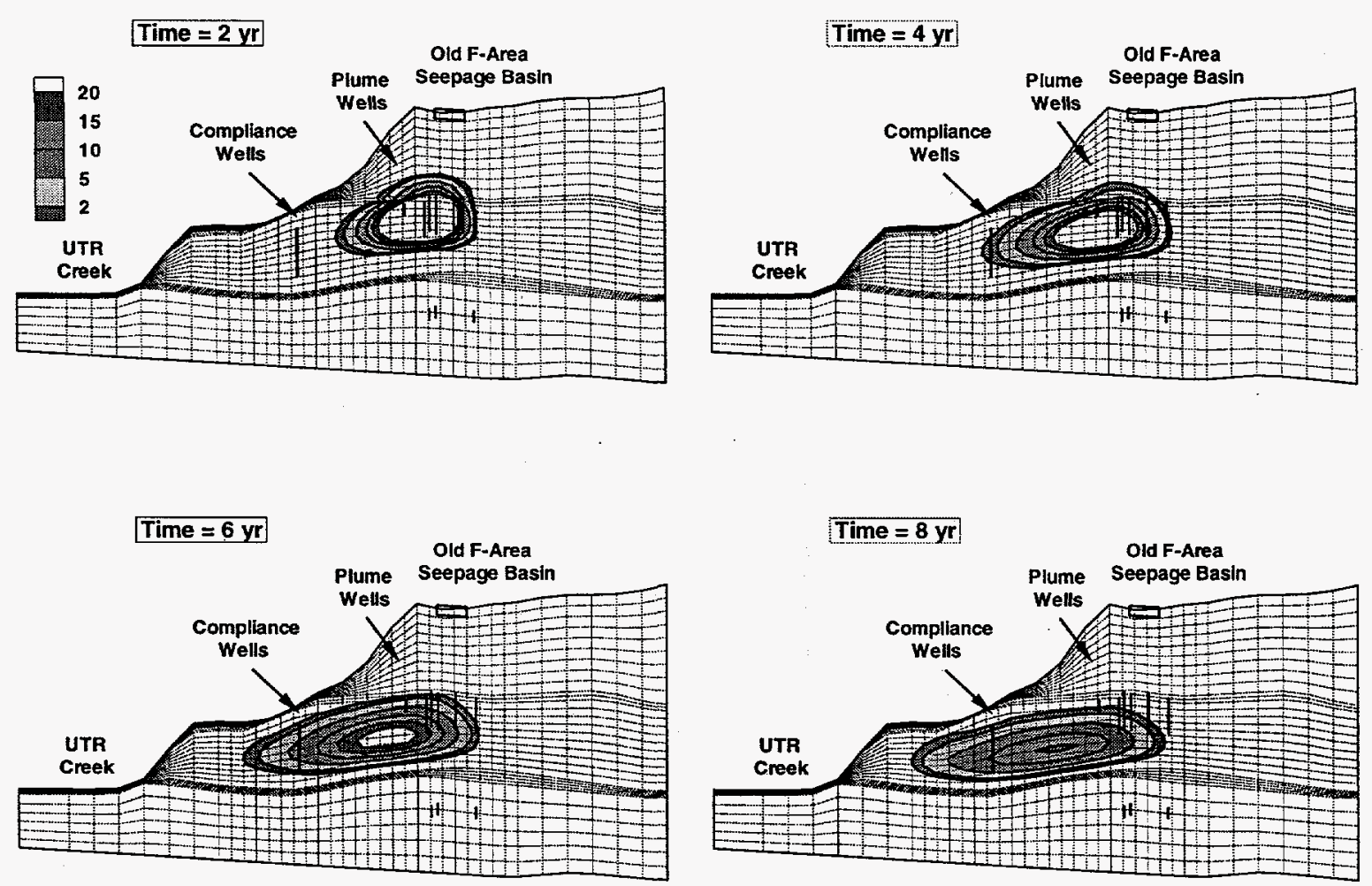

Figure 19: Predicted tritium plume conditions in two, four, six, and eight years (vertical cross-sectional view). 


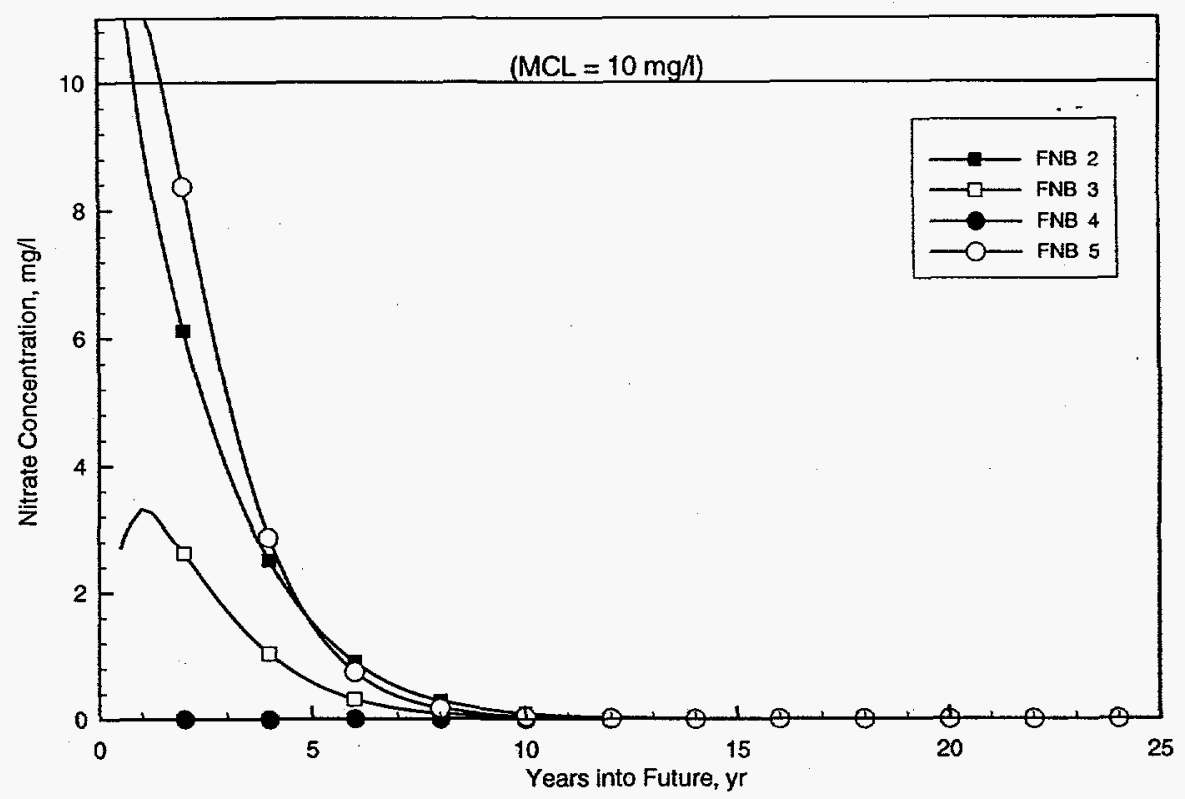

Figure 20: Predicted nitrate concentration at FNB Point of Compliance wells.

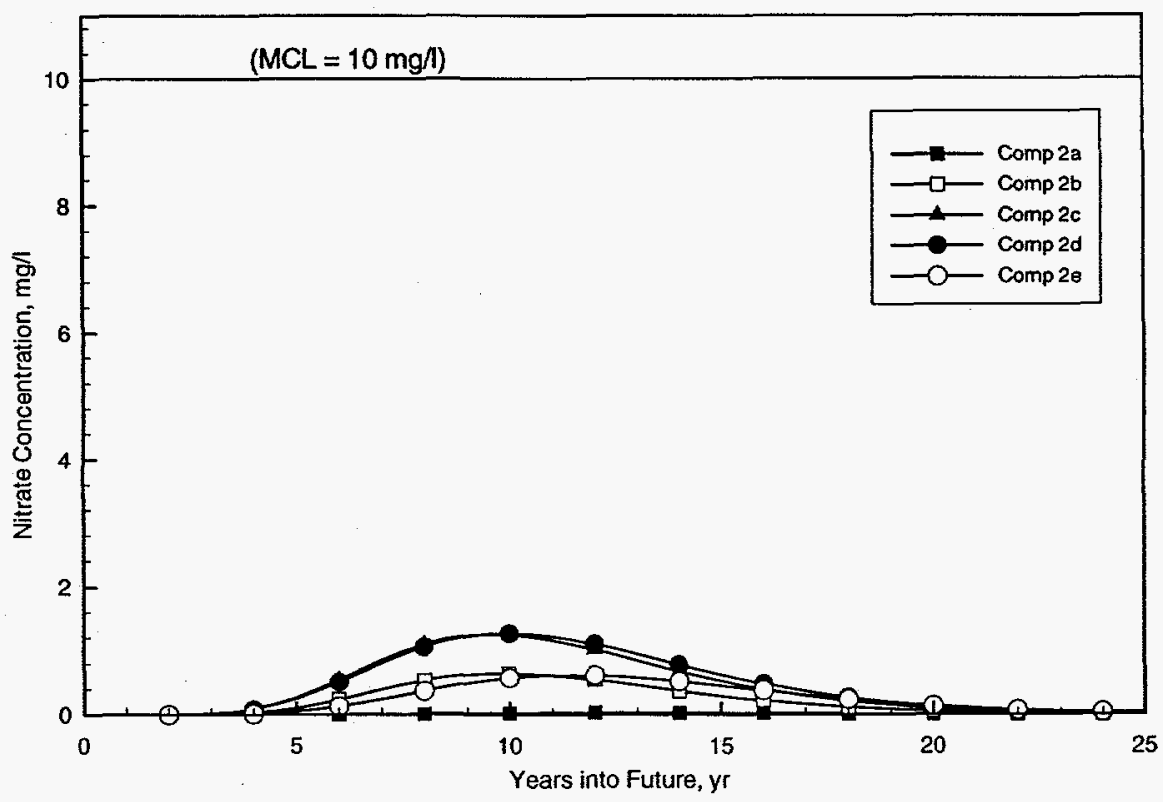

Figure 21: Predicted nitrate concentration at Compliance Boundary. 

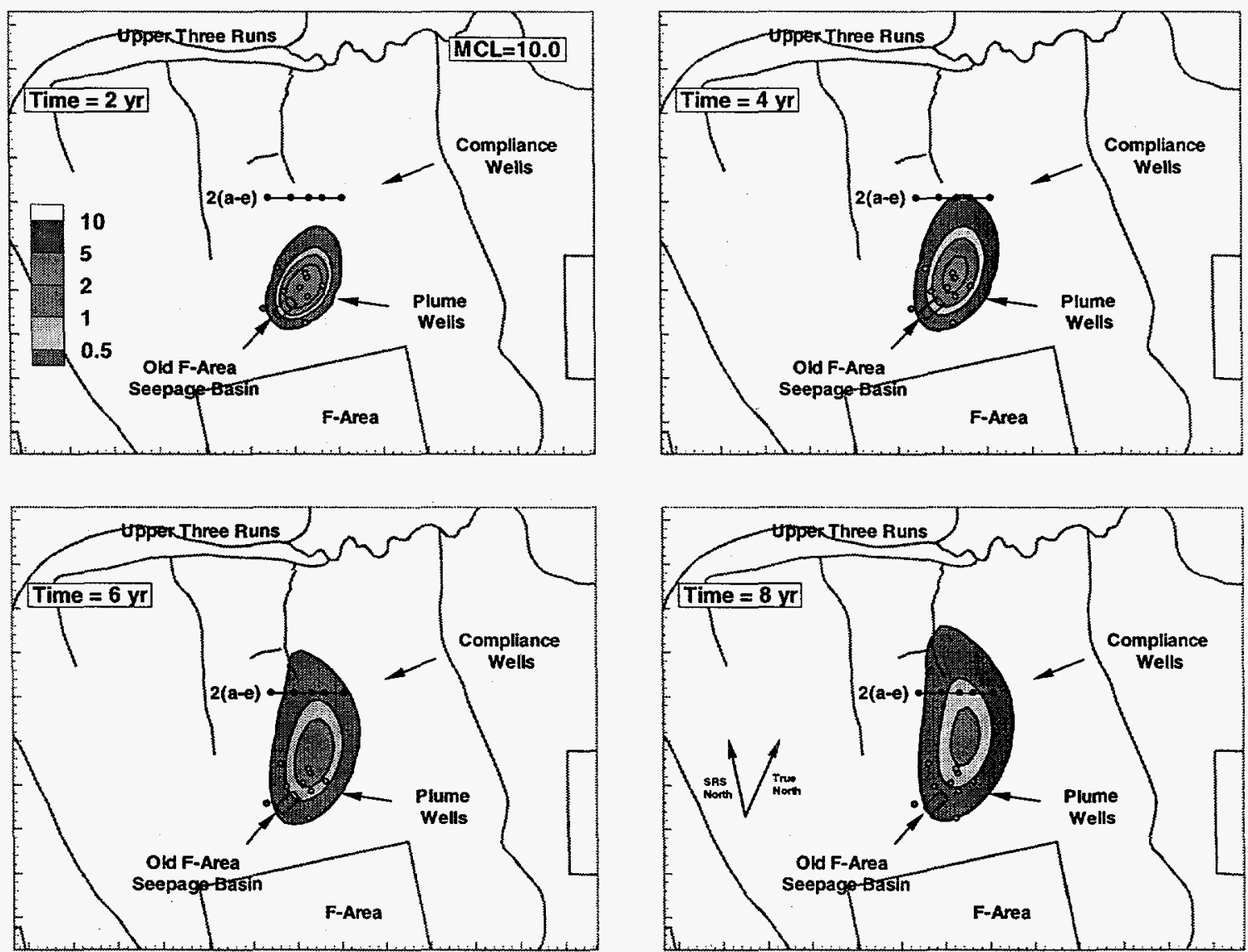

Figure 22: Predicted nitrate plume conditions in two, four, six, and eight years (plan view). 

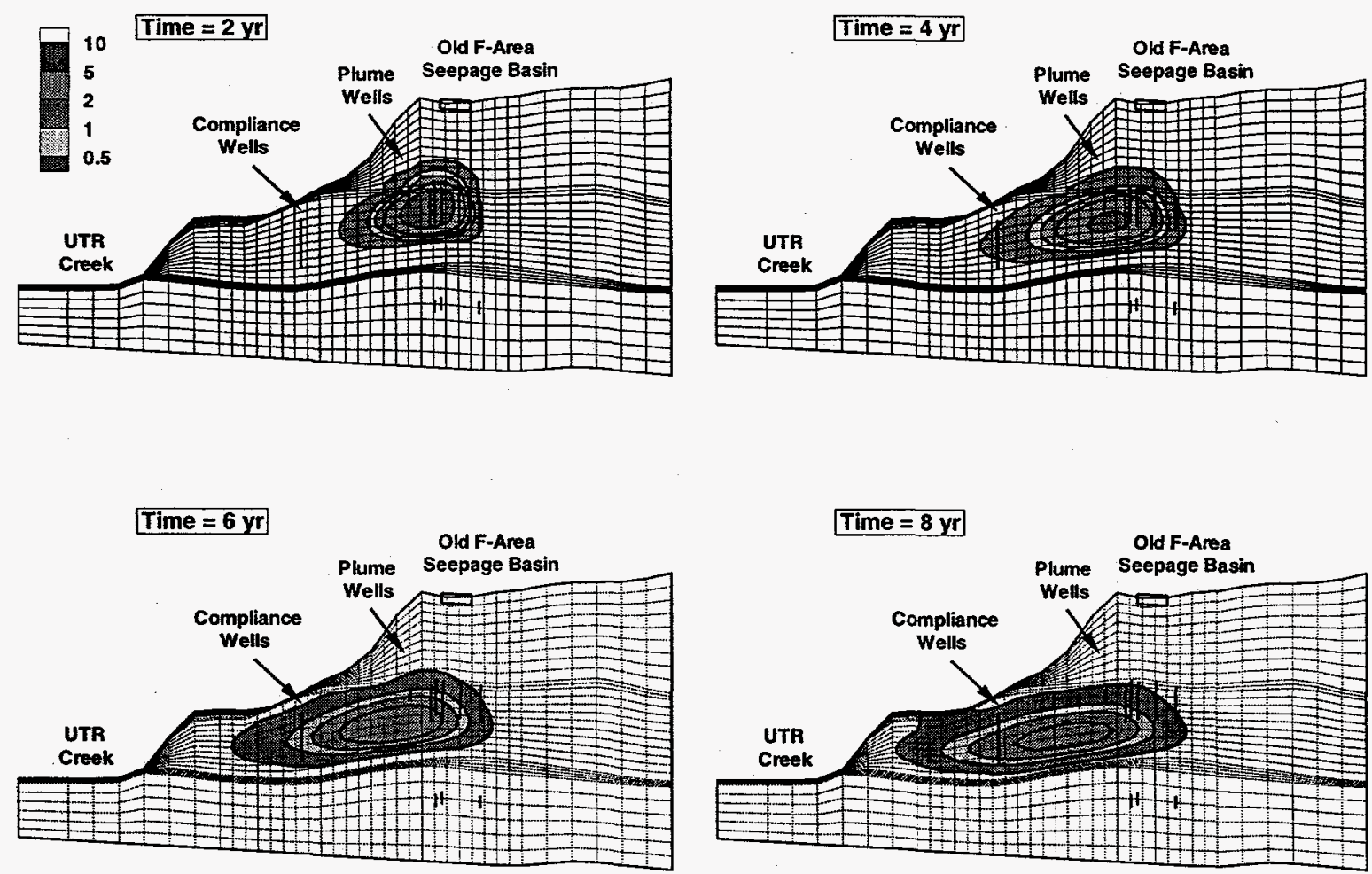

Figure 23: Predicted nitrate plume conditions in two, four, six, and eight years (vertical cross-sectional view). 


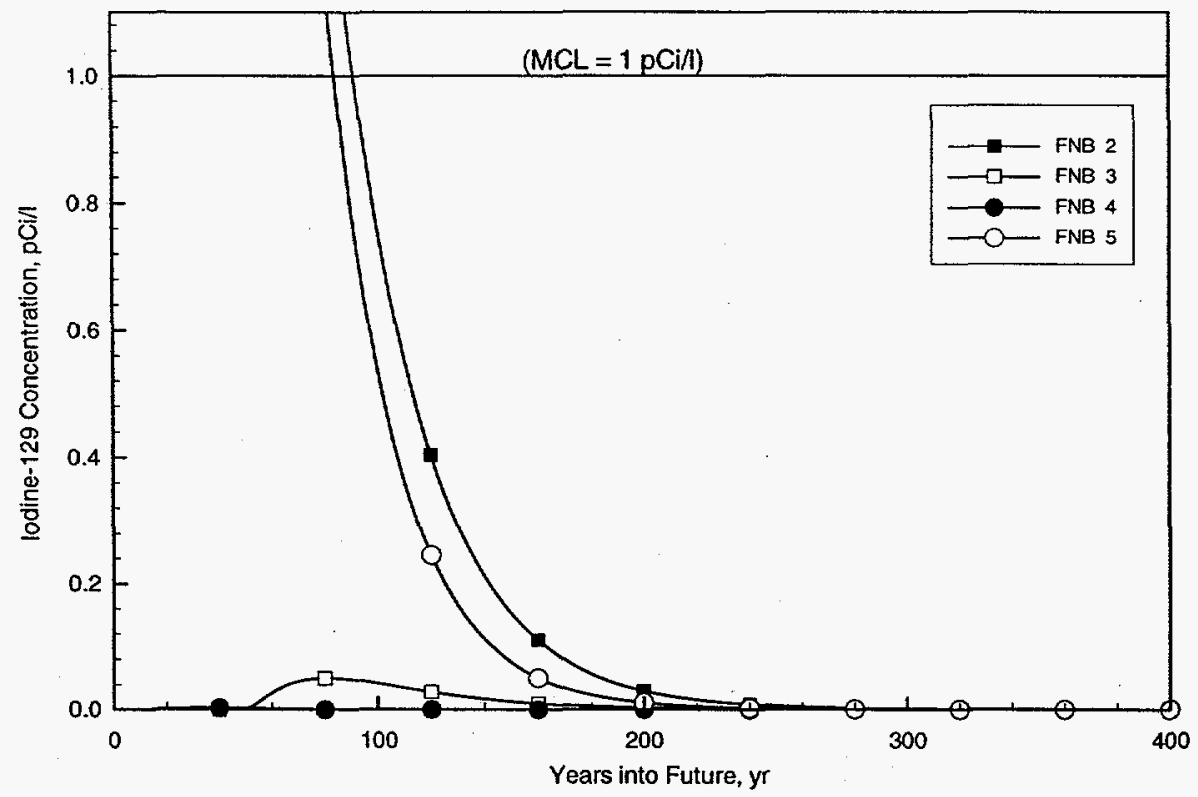

Figure 24: Predicted iodine-129 concentration at FNB Point of Compliance wells.

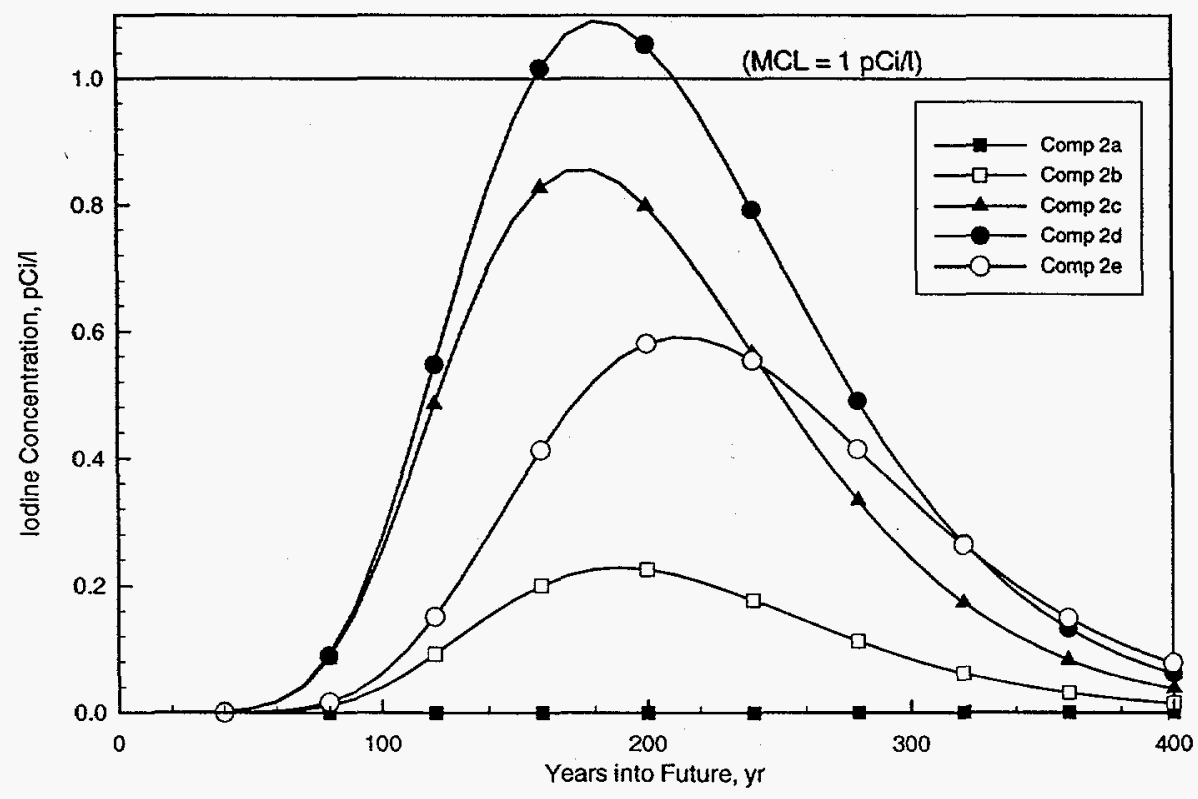

Figure 25: Predicted iodine-129 concentration at Compliance Boundary. 

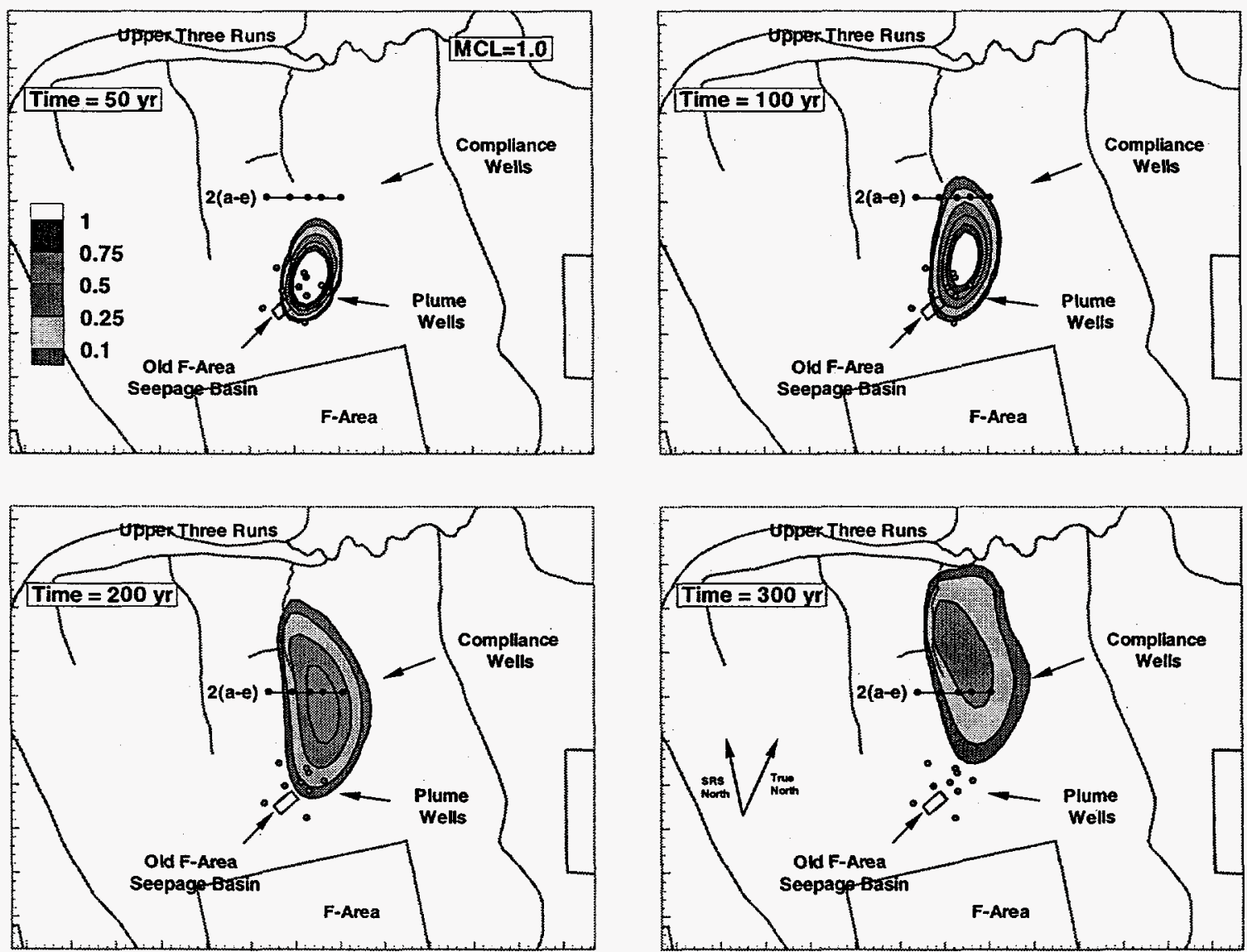

Figure 26: Predicted iodine-129 plume conditions in 50,100, 200, and 300 years (plan view). 

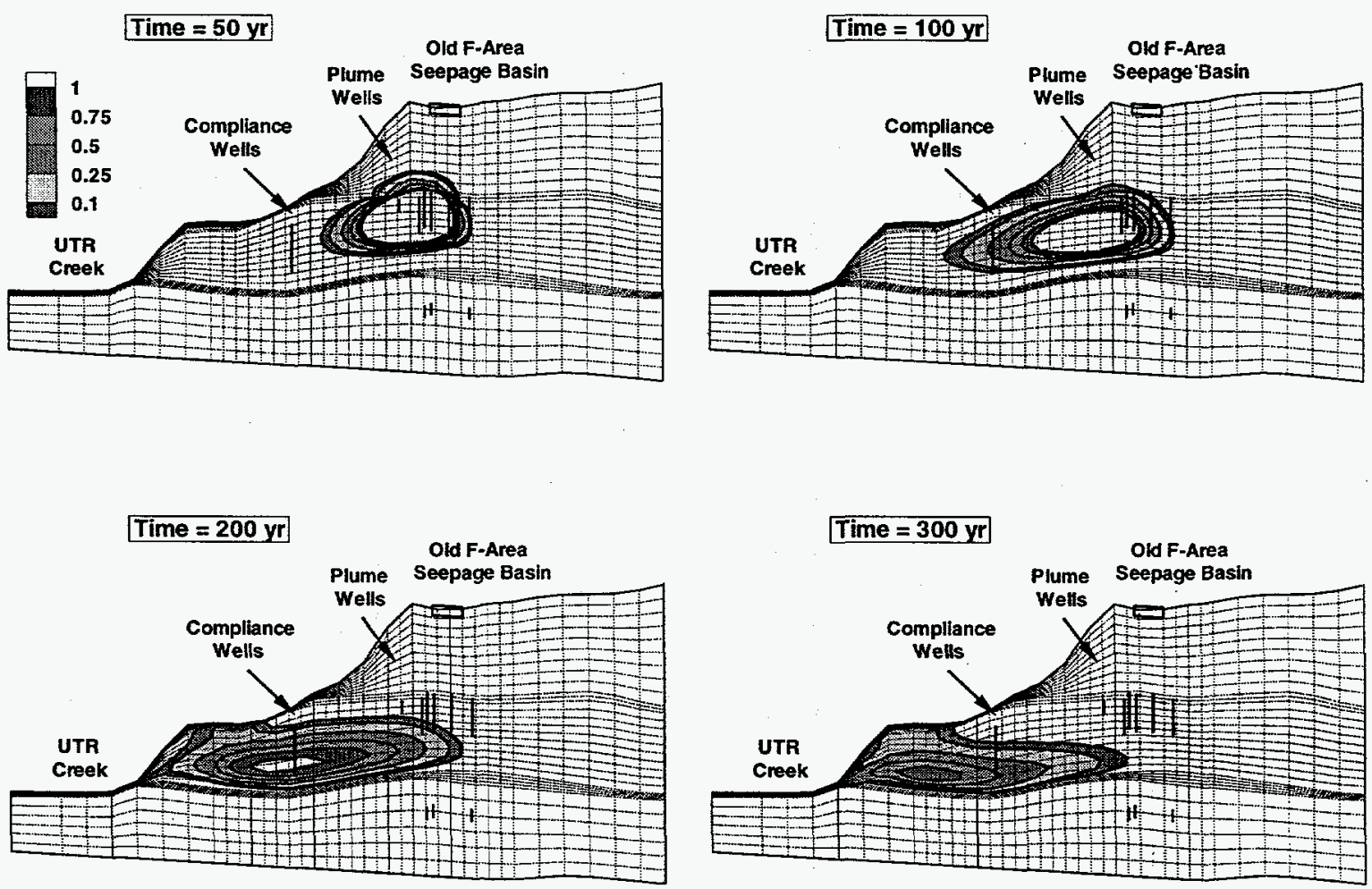

Figure 27: Predicted iodine-129 plume conditions in 50, 100, 200, and 300 years (vertical cross-sectional view). 


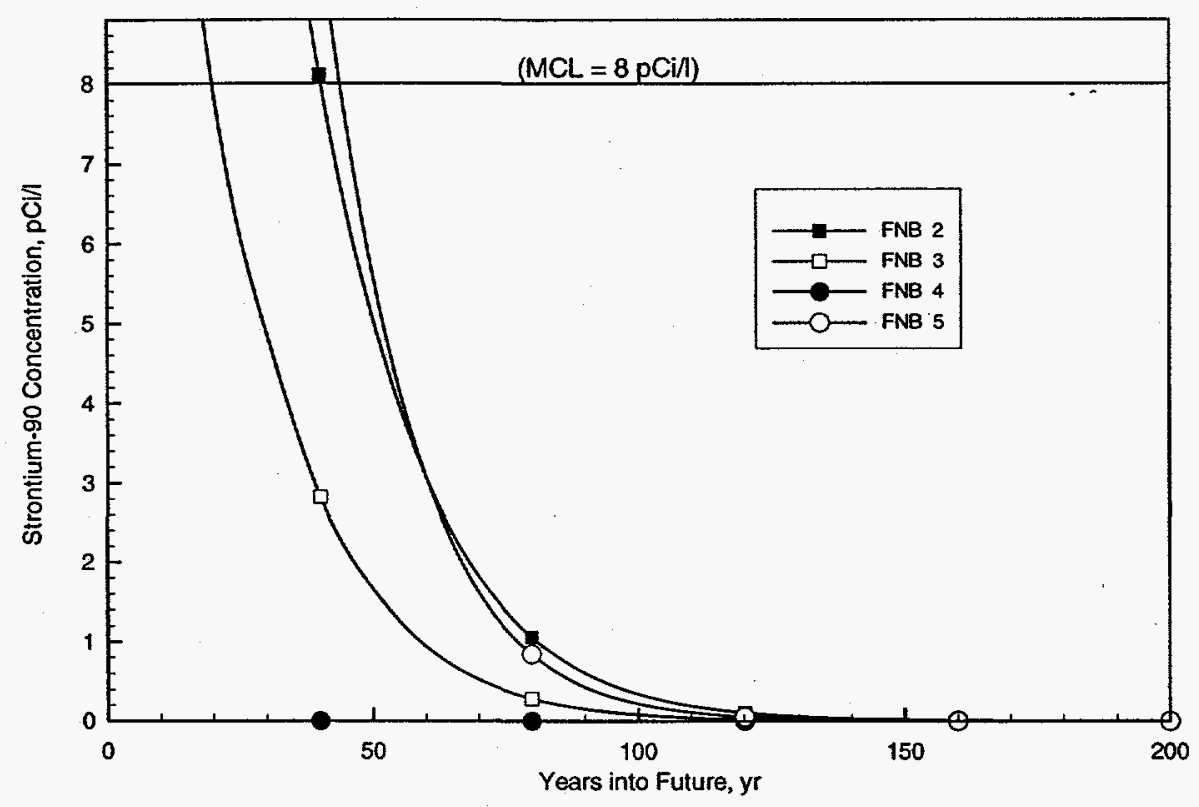

Figure 28: Predicted strontium-90 concentration at FNB Point of Compliance wells.

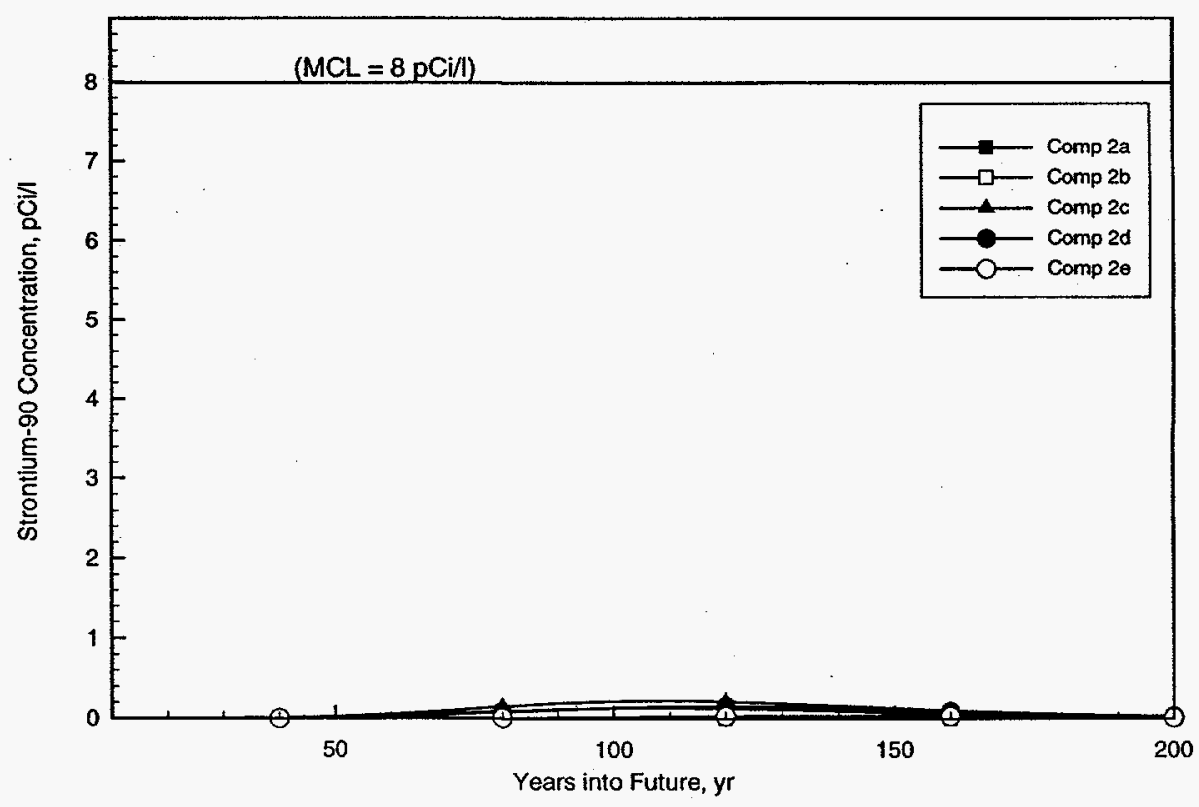

Figure 29: Predicted strontium-90 concentration at Compliance Boundary. 

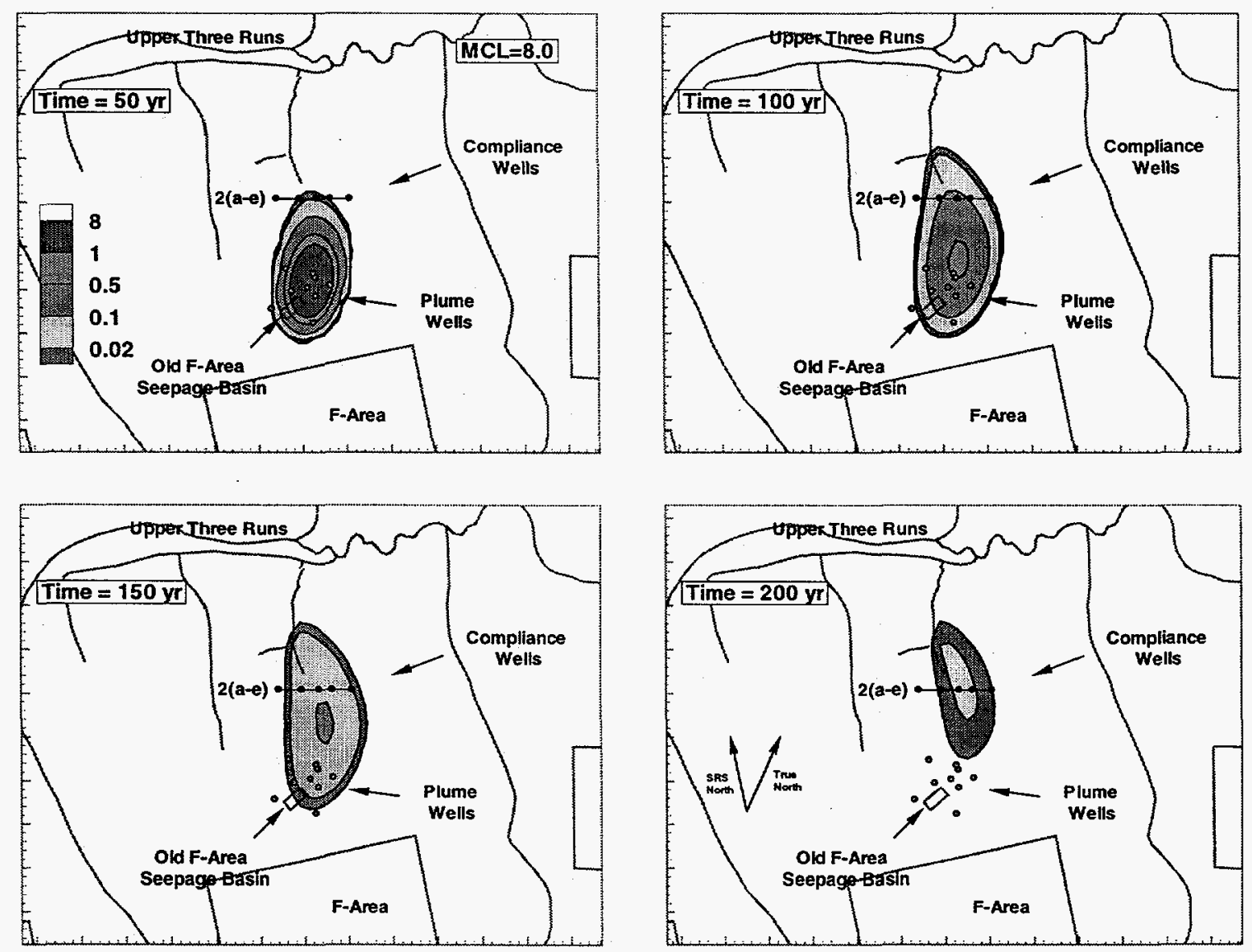

Figure 30: Predicted strontium-90 plume conditions in 50, 100, 150, and 200 years (plan view). 

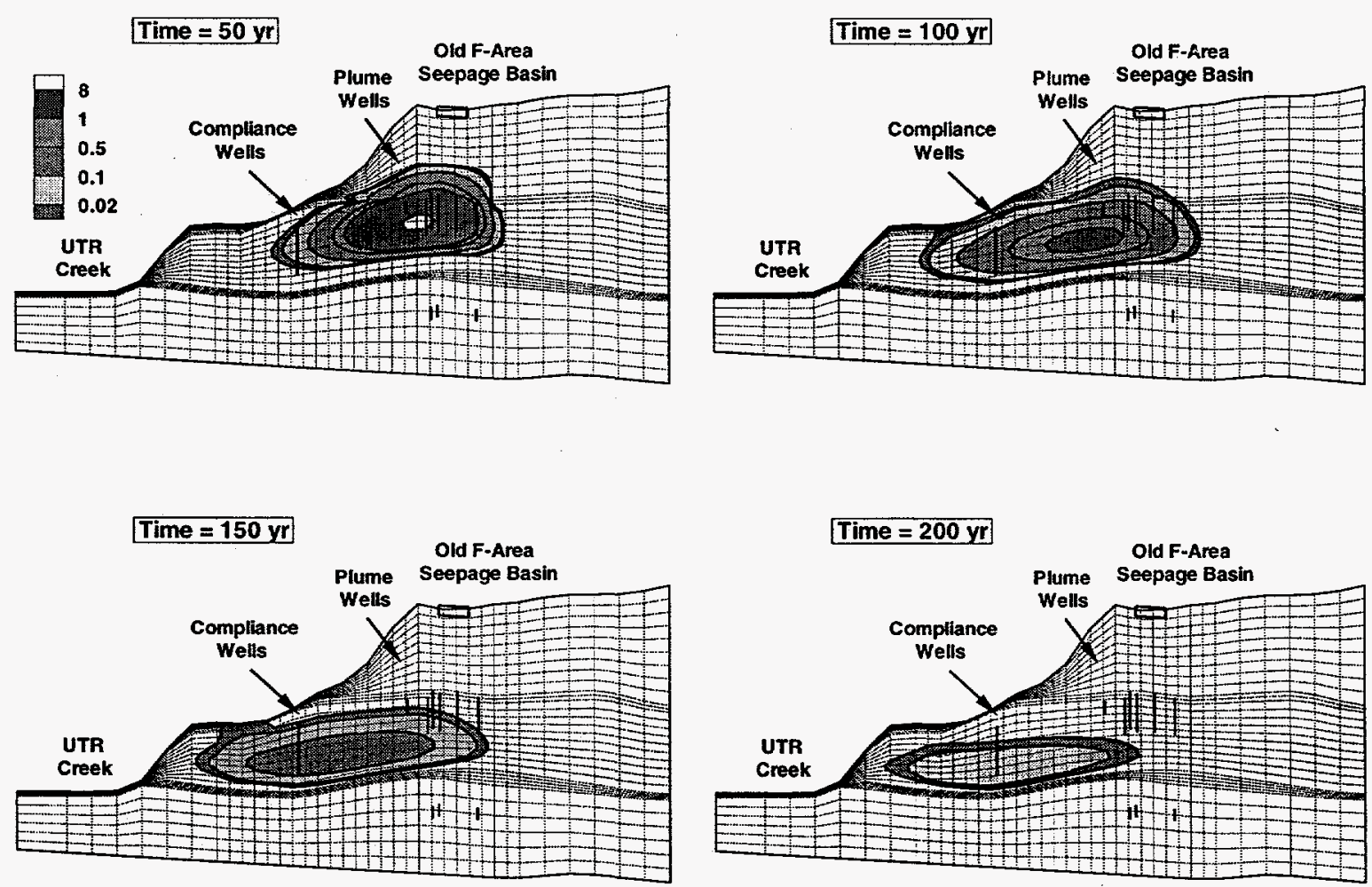

Figure 31: Predicted strontium-90 plume conditions in 50, 100, 150, and 200 years (vertical cross-sectional view). 


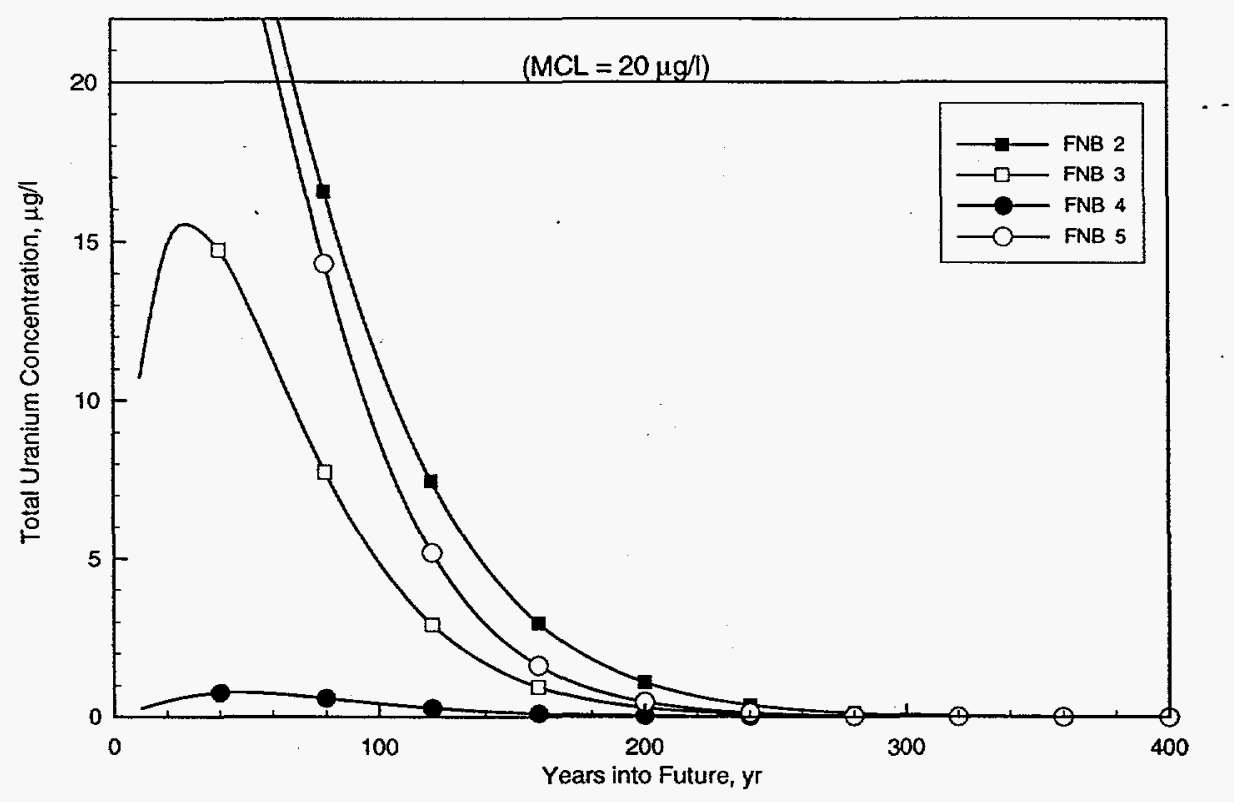

Figure 32: Predicted uranium (total) concentration at FNB Point of Compliance wells.

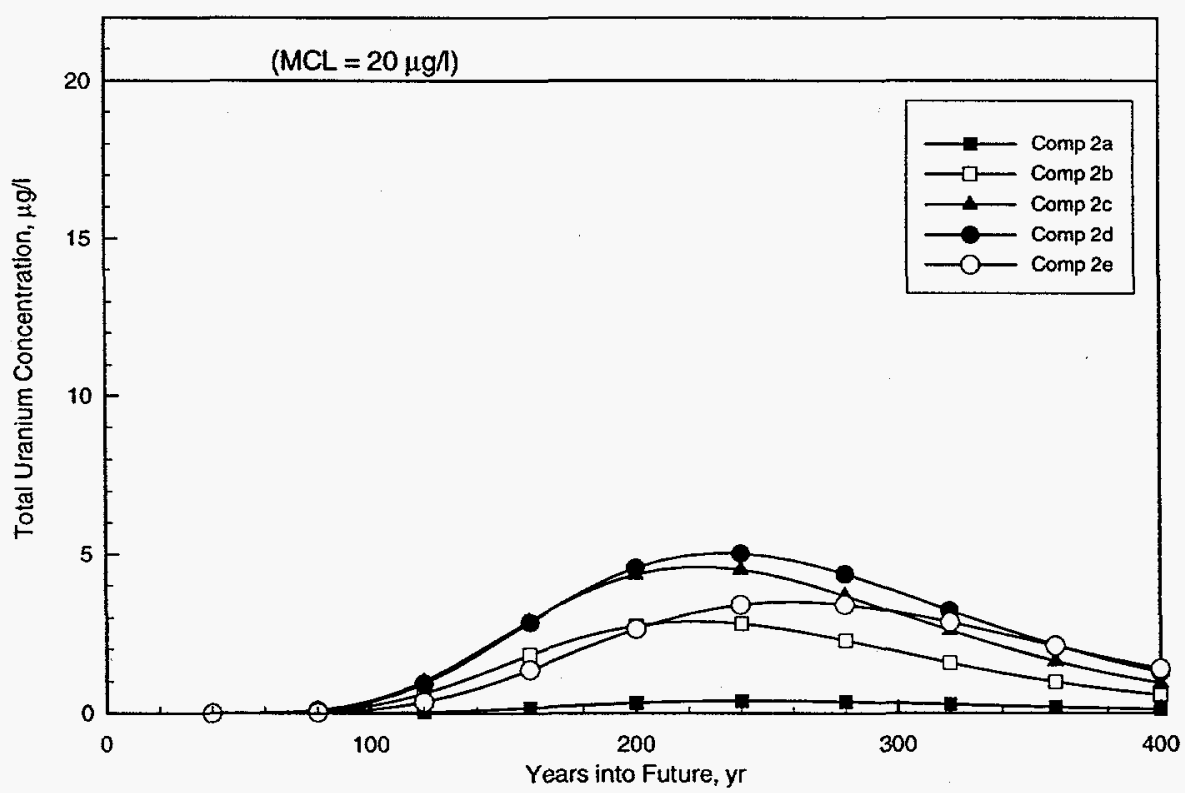

Figure 33: Predicted uranium (total) concentration at Compliance Boundary. 

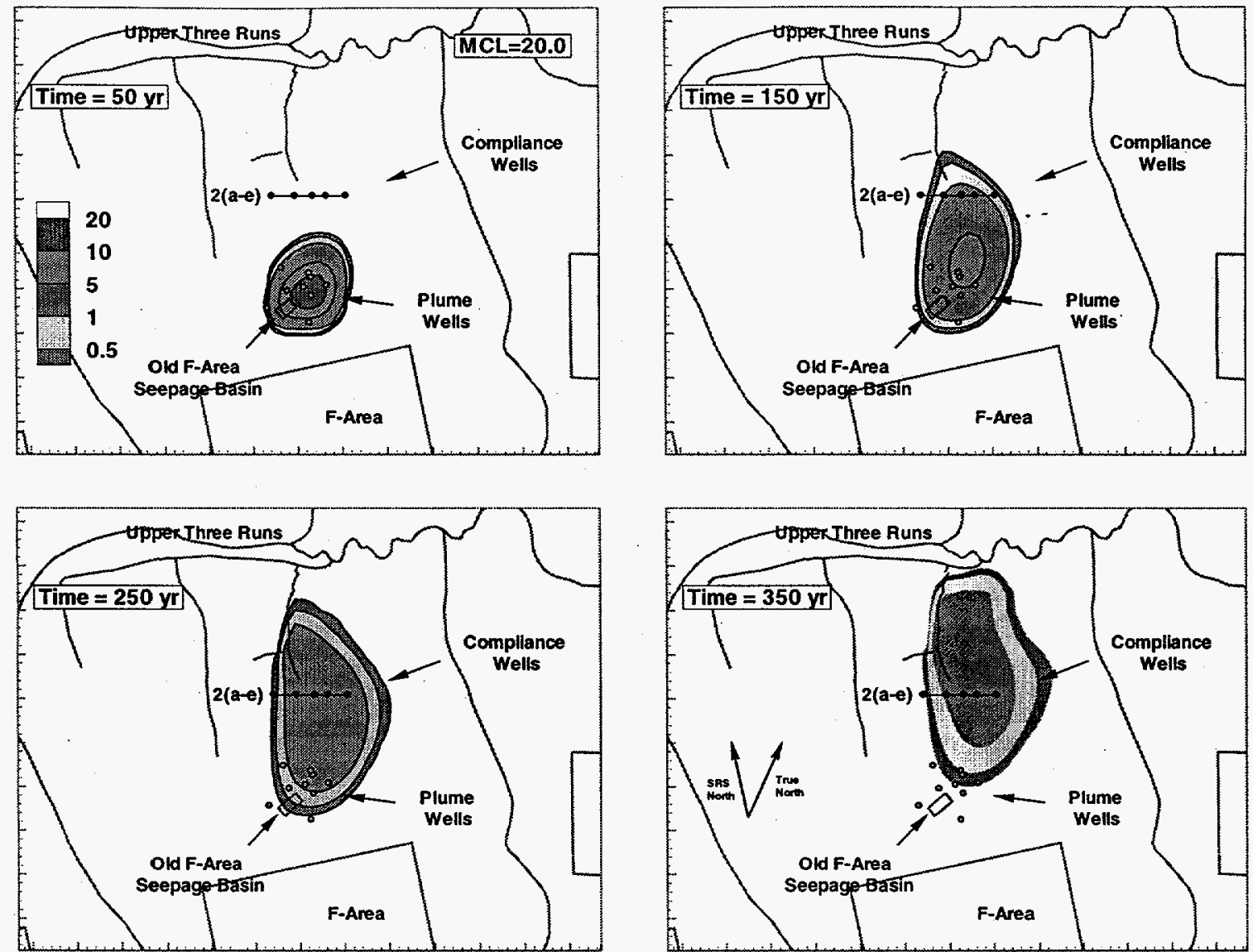

Figure 34: Predicted uranium (total) plume conditions in 50, 150, 250, and 350 years (plan view). 

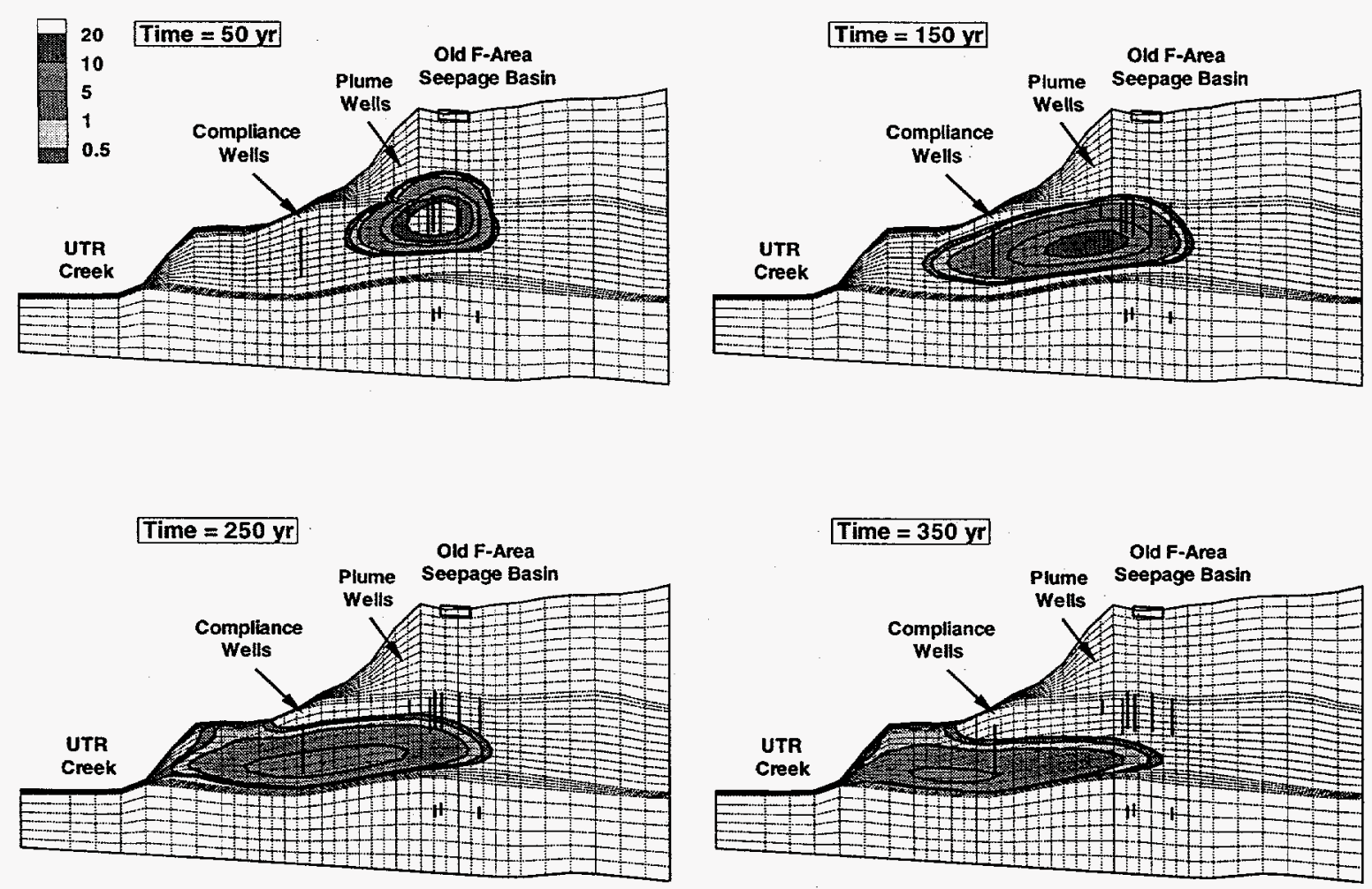

Figure 35: Predicted uranium (total) plume conditions in 50,150, 250, and 350 years (vertical cross-sectional view). 


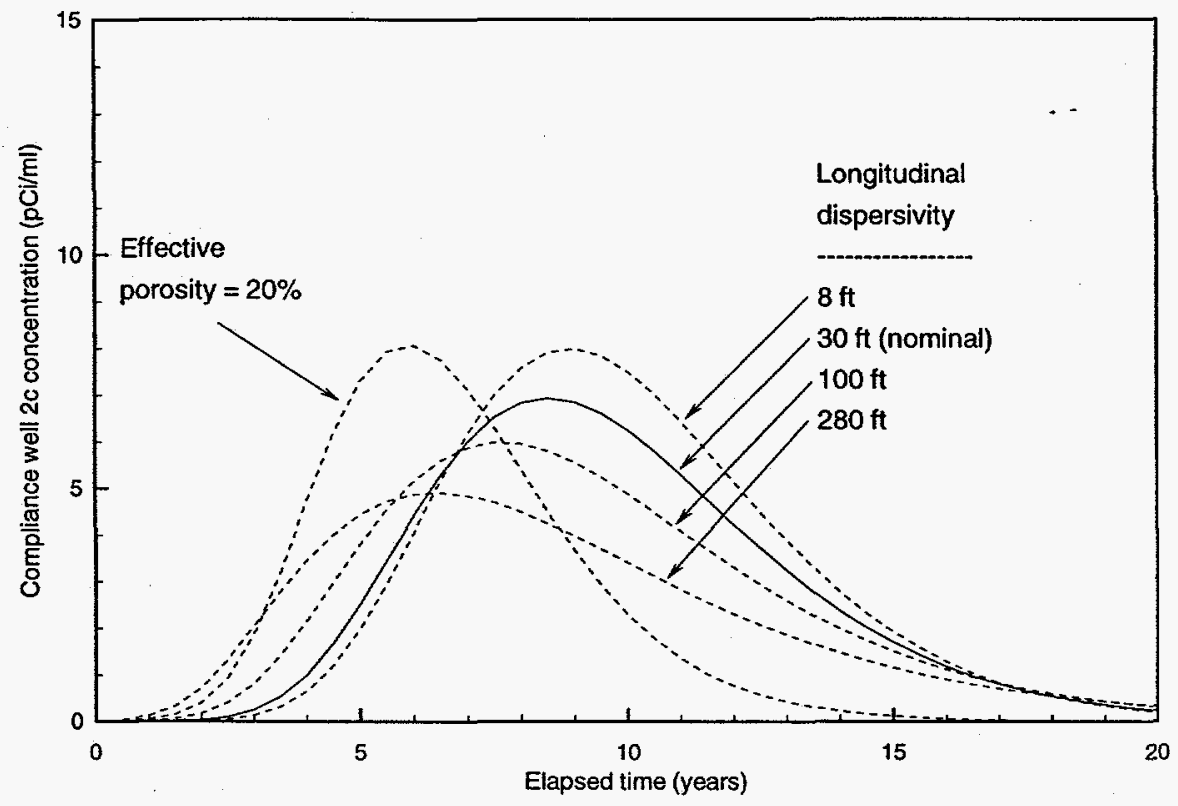

Figure 36: Results of sensitivity study for tritium.

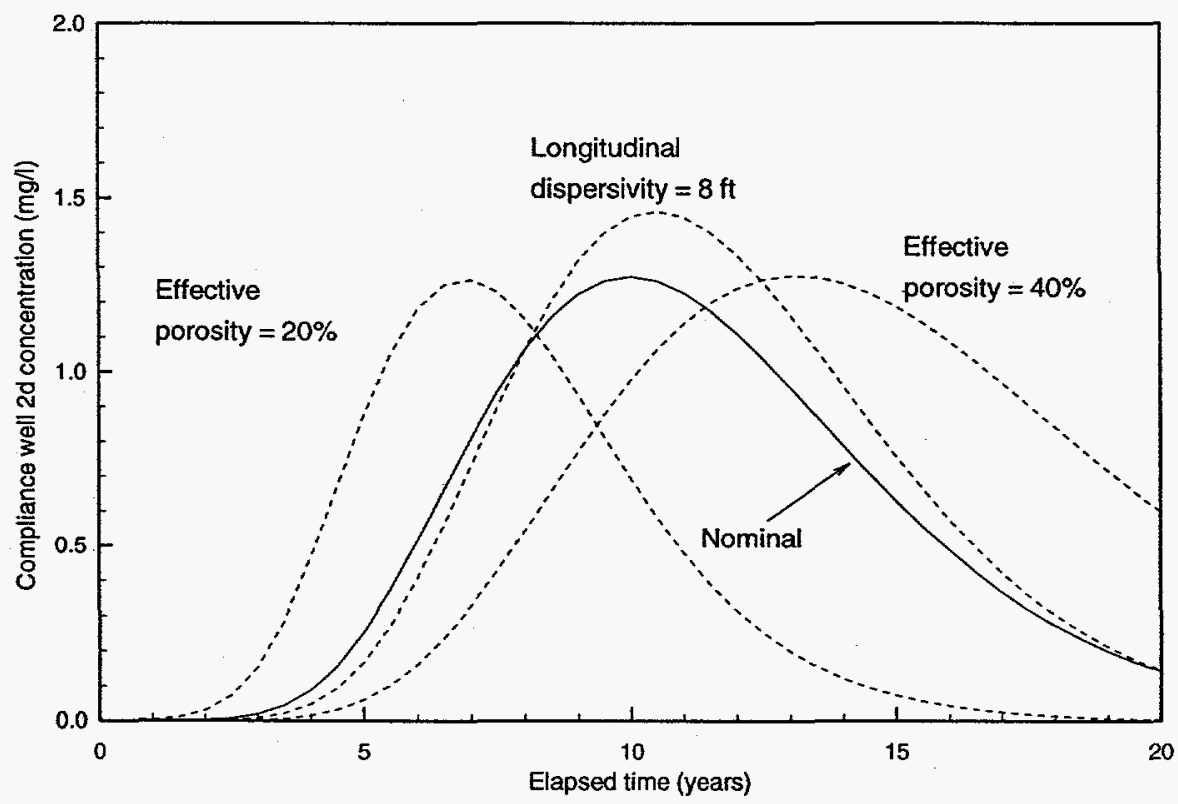

Figure 37: Results of sensitivity study for nitrate. 


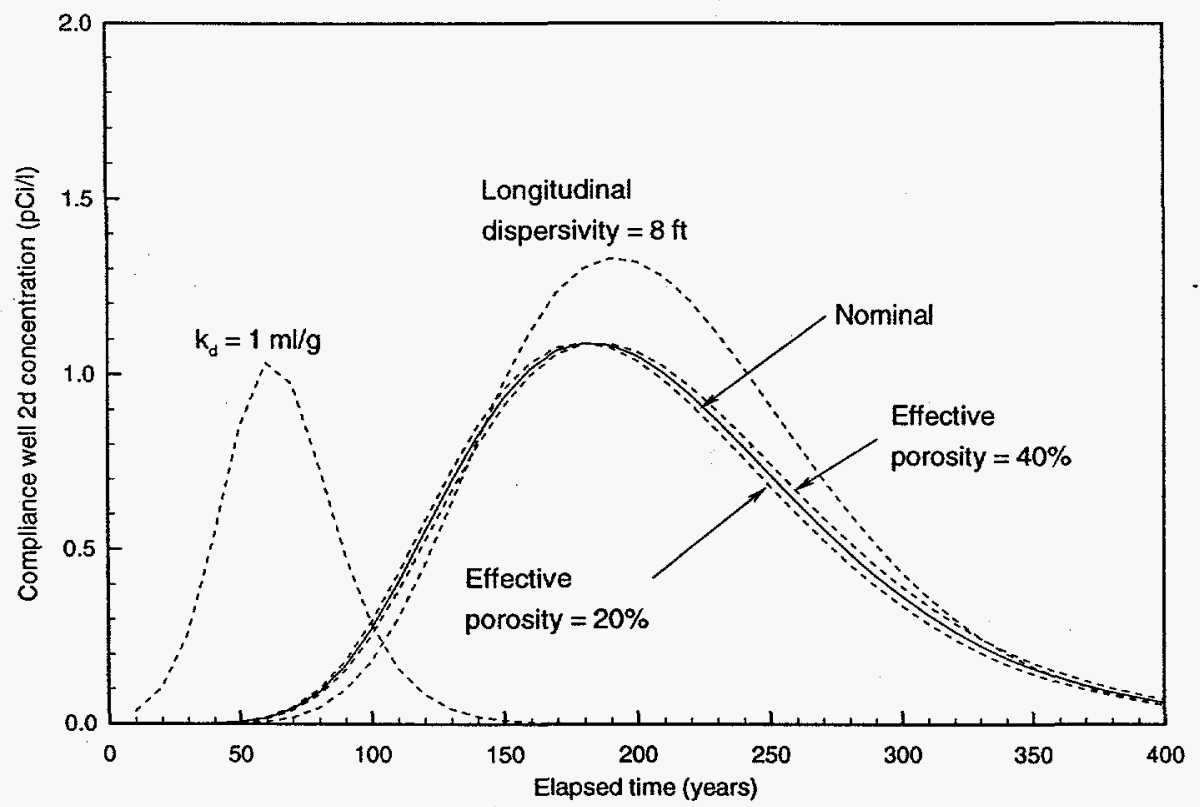

Figure 38: Results of sensitivity study for iodine-129.

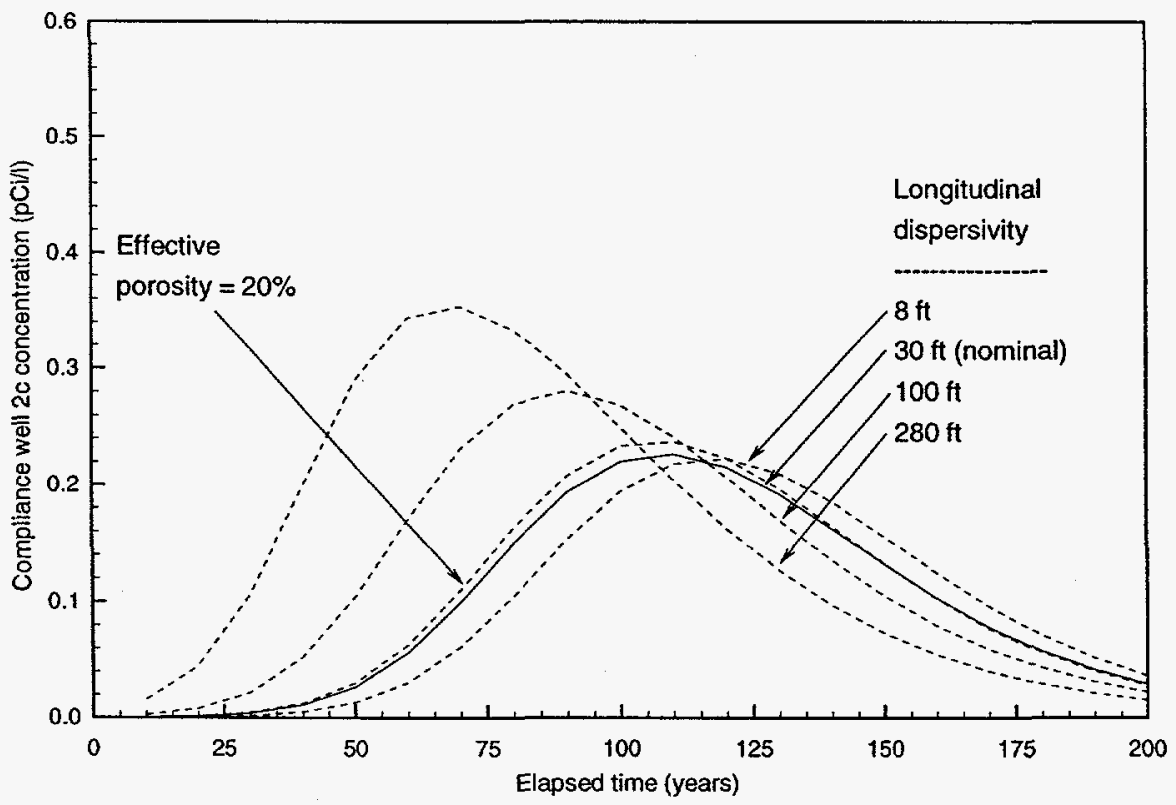

Figure 39: Results of sensitivity study for strontium-90. 


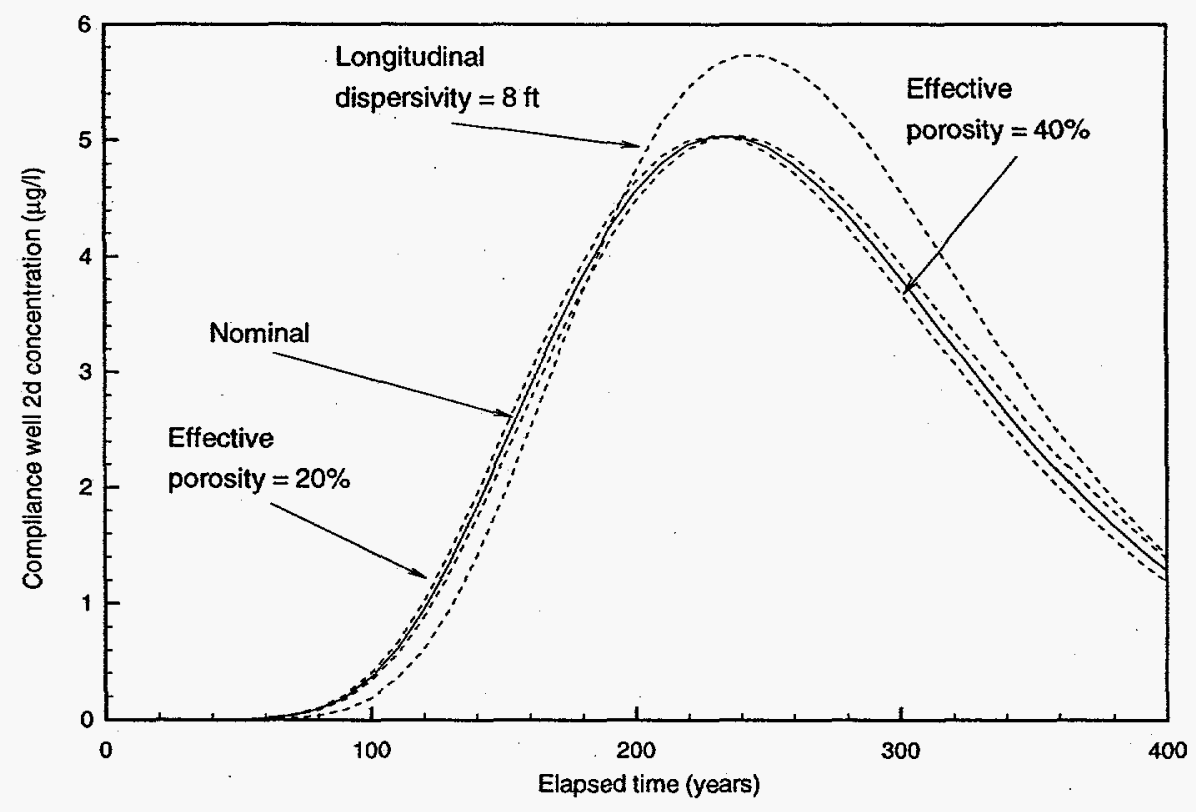

Figure 40: Results of sensitivity study for uranium (total). 


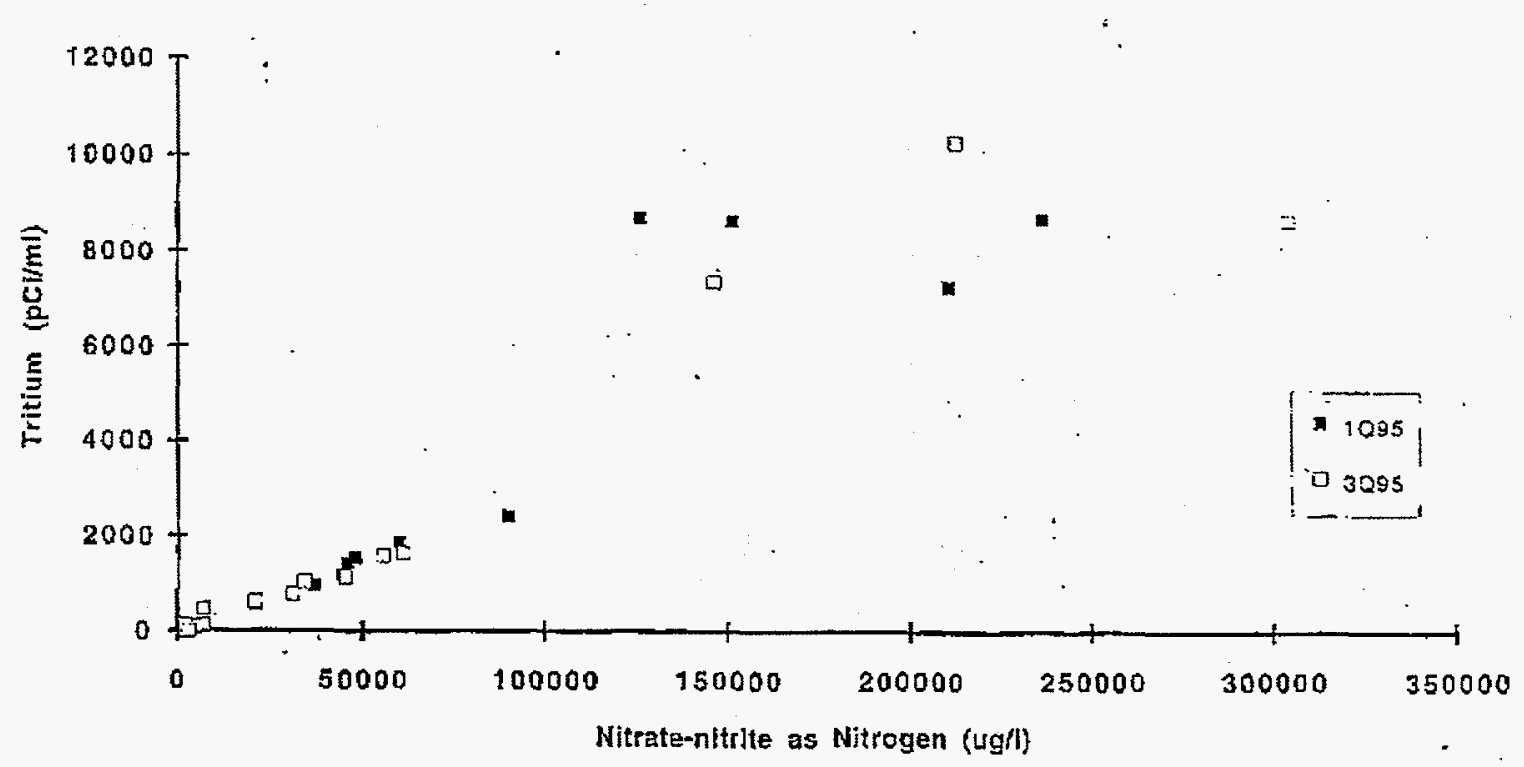

Figure 41: Plot of Tritium versus nitrate in groundwater of water table wells at F-Area Seepage Basin. 


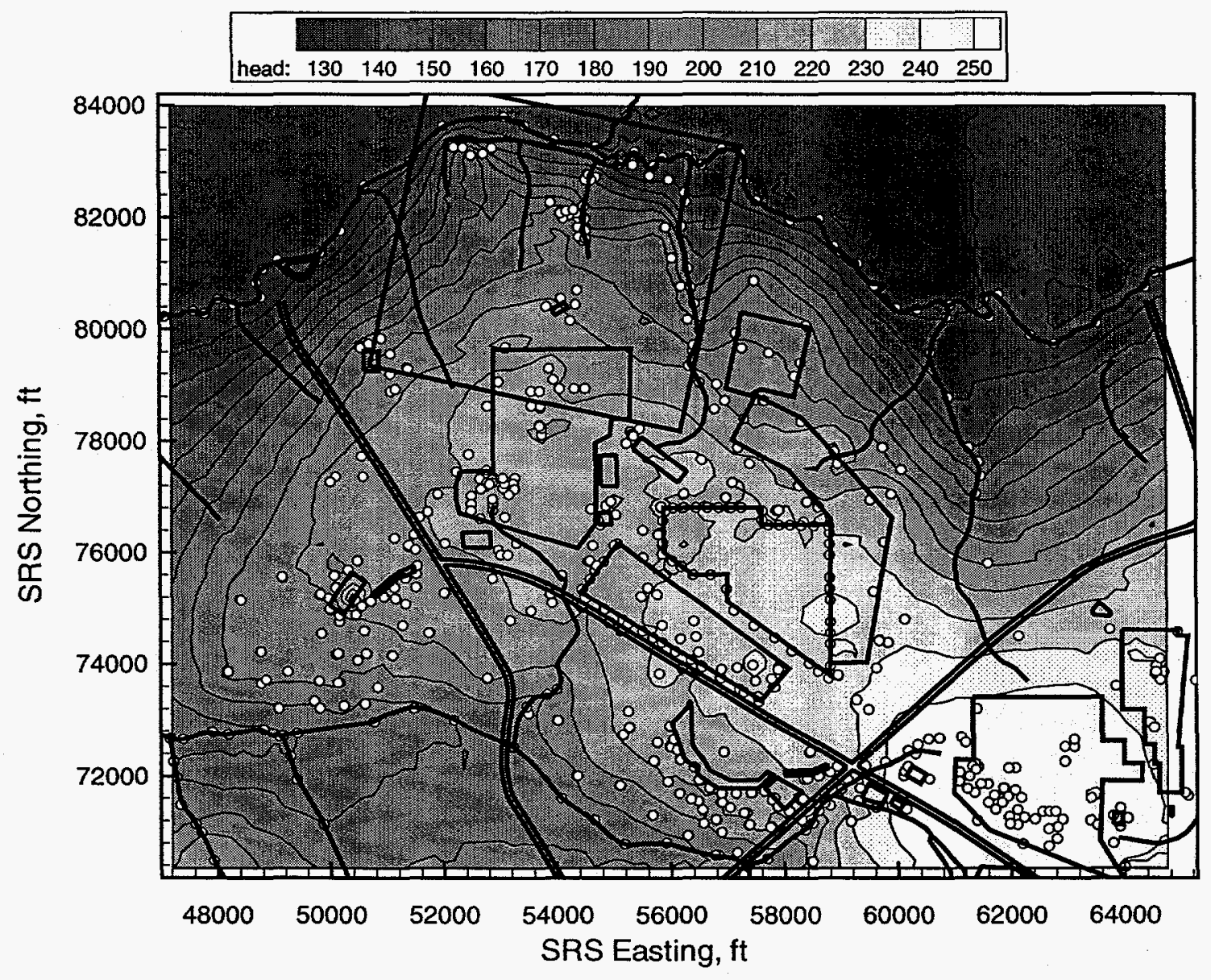

Figure 42: Contour plot of measured hydraulic head and seepline data from Upper Three Runs Aquifer $\left(\mathrm{IIB}_{1}\right.$ and $\left.\mathrm{IB}_{2}\right)$ within the GSA. 


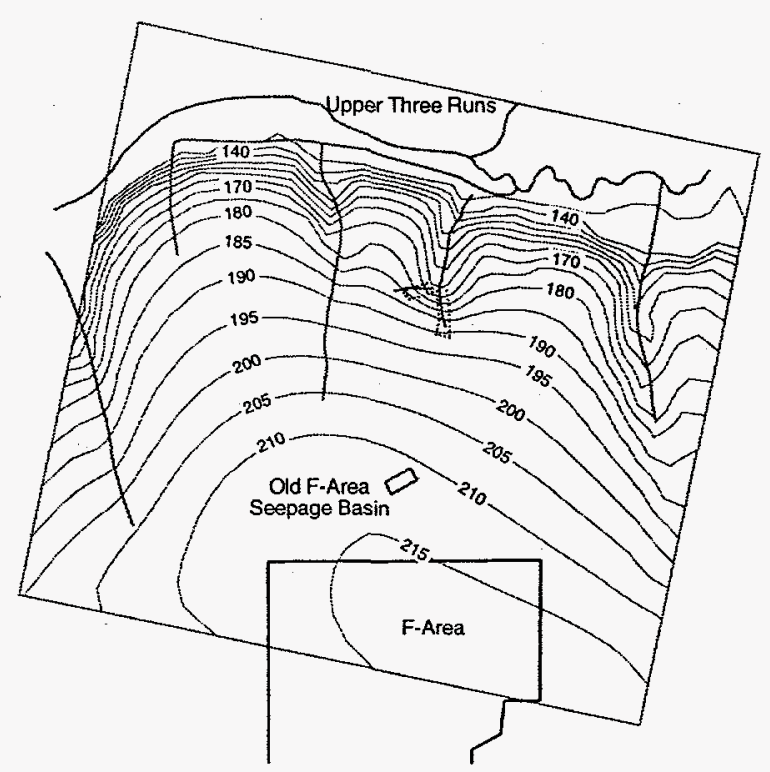

Figure 43: Contour plot of simulated hydraulic head in the "lower" aquifer zone $\left(\mathrm{IB}_{1}\right)$.

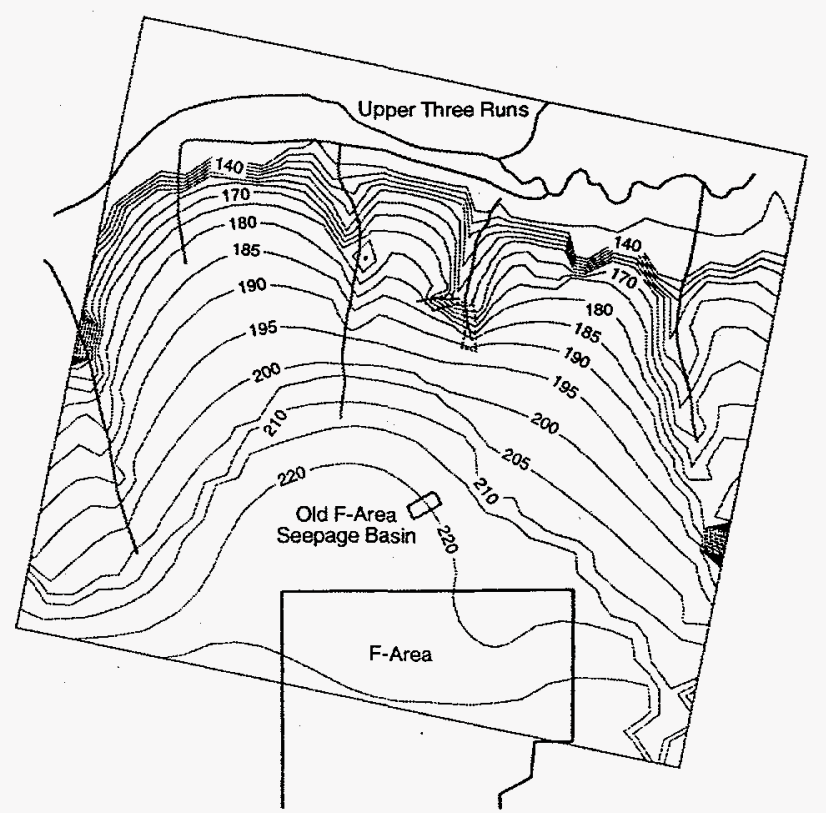

Figure 44: Contour plot of simulated hydraulic head in the water table. 